OPEN ACCESS

Edited by:

George E. Barreto,

University of Limerick, Ireland

Reviewed by:

Shih-Heng Chen,

National Institute of Environmental Health Sciences (NIEHS), United States

Luca Steardo,

University Magna Graecia of

Catanzaro, Italy

Haroon Badshah,

Abdul Wali Khan University Mardan,

Pakistan

*Correspondence:

Silvia Lima Costa

costas/@ufba.br;

costas12011@gmail.com

Received: 27 December 2019 Accepted: 08 April 2020 Published: 15 May 2020

Citation:

Dourado NS, Souza CS, de Almeida MMA, Bispo da Silva A, dos Santos BL, Silva VDA, De Assis AM, da Silva JS, Souza DO, Costa MFD,

Butt AM and Costa SL

(2020) Neuroimmunomodulatory and

Neuroprotective Effects of the

Flavonoid Apigenin in in vitro Models of Neuroinflammation Associated With Alzheimer's Disease. Front. Aging Neurosci. 12:119. doi: 10.3389/fnagi.2020.00119

\section{Neuroimmunomodulatory and Neuroprotective Effects of the Flavonoid Apigenin in in vitro Models of Neuroinflammation Associated With Alzheimer's Disease}

Naiara Silva Dourado ${ }^{1}$, Cleide dos Santos Souza ${ }^{1,2}$, Monique Marylin Alves de Almeida ${ }^{1}$, Alessandra Bispo da Silva ${ }^{1}$, Balbino Lino dos Santos ${ }^{1,3}$, Victor Diogenes Amaral Silva ${ }^{1,4}$, Adriano Martimbianco De Assis ${ }^{4,5,6}$, Jussemara Souza da Silva ${ }^{6}$, Diogo Onofre Souza ${ }^{4,6}$, Maria de Fatima Dias Costa ${ }^{1,7}$, Arthur Morgan Butt ${ }^{8}$ and Silvia Lima Costa ${ }^{1,4,7 *}$

\begin{abstract}
${ }^{1}$ Laboratory of Neurochemistry and Cellular Biology, Institute of Health Sciences, Av. Reitor Miguel Calmon S/N, Federal University of Bahia (UFBA), Salvador, Brazil, ${ }^{2}$ Sheffield Institute of Translational Neuroscience (SITraN), The University of Sheffield, Sheffield, United Kingdom, ${ }^{3}$ College of Nursing, Federal University of Vale do São Francisco (UNIVASF), Petrolina, Brazil, ${ }^{4}$ INCT for Excitotoxicity and Neuroprotection (INCT-EN, BR), Porto Alegre, Brazil, ${ }^{5}$ Postgraduate in Health and Behavior, Catholic University of Pelotas (UCPEL), Pelotas, Brazil, ${ }^{6}$ Department of Biochemistry, Institute of Basic Health Sciences, Federal University of Rio Grande do Sul (UFRGS), Porto Alegre, Brazil, ${ }^{7}$ Instituto Nacional de Ciência e Tecnologia em Excitotoxicidade e Neuroproteção (INCT) - Translational Neuroscience (INCT-TN, BR), Porto Alegre, Brazil, ${ }^{8}$ School of Pharmacy and Biomedical Sciences, University of Portsmouth, Portsmouth, United Kingdom
\end{abstract}

Neurodegenerative disorders (ND) are characterized by the progressive and irreversible loss of neurons. Alzheimer's Disease (AD) is the most incident age-related ND, in which the presence of a chronic inflammatory compound seems to be related to its pathogenesis. Different stimuli in the central nervous system (CNS) can induce activation, proliferation, and changes in phenotype and glial function, which can be modulated by anti-inflammatory agents. Apigenin (4,5,7-trihydroxyflavone) is a flavonoid found in abundance in many fruits and vegetables, that has shown important effects upon controlling the inflammatory response. This study evaluated the neuroprotective and neuroimmunomodulatory potential of apigenin using in vitro models of neuroinflammation associated with AD. Co-cultures of neurons and glial cells were obtained from the cortex of newborn and embryonic Wistar rats. After 26 days in vitro, cultures were exposed to lipopolysaccharide (LPS; $1 \mu \mathrm{g} / \mathrm{ml}$ ), or $\mathrm{IL}-1 \beta(10 \mathrm{ng} / \mathrm{ml})$ for $24 \mathrm{~h}$, or to $A \beta$ oligomers $(500 \mathrm{nM})$ for $4 \mathrm{~h}$, and then treated with apigenin $(1 \mu \mathrm{M})$ for further $24 \mathrm{~h}$. It was observed that the treatment with apigenin preserved neurons and astrocytes integrity, determined by Rosenfeld's staining and immunocytochemistry for $\beta$-tubulin III and GFAP, respectively. Moreover, it was observed by Fluoro-Jade-B and caspase-3 immunostaining that apigenin was not neurotoxic and has a neuroprotective effect against inflammatory damage. Additionally, 
apigenin reduced microglial activation, characterized by inhibition of proliferation (BrdU+ cells) and modulation of microglia morphology (lba-1 + cells), and decreased the expression of the M1 inflammatory marker CD68. Moreover, as determined by RT-qPCR, inflammatory stimuli induced by IL-1 $\beta$ increased the mRNA expression of IL-6, IL-1 $\beta$, and CCL5, and decreased the mRNA expression of IL-10. Contrary, after treatment with apigenin in inflammatory stimuli (IL-1 $\beta$ or LPS) there was a modulation of the mRNA expression of inflammatory cytokines, and reduced expression of OX42, IL-6 and gp130. Moreover, apigenin alone and after an inflammatory stimulus with IL-1 $\beta$ also induced the increase in the expression of brain-derived neurotrophic factor (BDNF), an effect that may be associated with anti-inflammatory and neuroprotective effects. Together these data demonstrate that apigenin presents neuroprotective and anti-inflammatory effects in vitro and might represent an important neuroimmunomodulatory agent for the treatment of neurodegenerative conditions.

\section{Keywords: neuroinflammation, neuroprotection, anti-inflammatory, microglia, flavonoids}

\section{INTRODUCTION}

Neurodegenerative disorders (ND) age-related represent a serious public health problem in which incidence has increased due to augmented population aging. These disorders are associated with the progressive loss of neurons (Procaccini et al., 2016) and studies suggest that exacerbated inflammatory response could be the major cause behind neurodegeneration (Doty et al., 2015).

Among the cells that comprise the central nervous system (CNS), astrocytes and microglia have been proved for playing a critical role in physiology and disease (Allen and Barres, 2009), because these glial cells are capable to respond actively against toxins, infections and injuries to the CNS (Burda and Sofroniew, 2014; Kinney et al., 2018). Glial activation is a protective mechanism that regulates tissue repair in the early stage of neurodegeneration (Streit, 2005). However, excessive and prolonged activation contributes to a chronic neuroinflammatory response (Kraft and Harry, 2011), that might be involved in the onset and progression of most ND, such as Amyotrophic lateral sclerosis, Parkinson's disease and Alzheimer's disease (Heneka et al., 2015; Ghadery et al., 2017; Shi and Holtzman, 2018; Jara et al., 2019; McCauley and Baloh, 2019). According to van Horssen et al. (2019), microglial and astrocytic activation leads to the production of inflammatory mediators such as cytokines, chemokines, reactive oxygen and nitrogen species, which eventually contribute to neuronal death.

Beyond the diseases that imply greater socioeconomic impact, Alzheimer's disease (AD) is the most frequent neurodegenerative disorder in the world characterized by the accumulation of $\beta$-amyloid $(\mathrm{A} \beta$ ) protein in the brain parenchyma, the formation of neurofibrillary tangles, glial activation and production of inflammatory mediators such as NO, interleukin $1 \beta$ (IL-1 $\beta$ ), interleukin 6 (IL-6) and tumor necrosis factor- $\alpha$ (TNF- $\alpha$; Zotova et al., 2013; Alasmari et al., 2018). Despite new therapeutic approaches carried out over the past few years, treatments for $\mathrm{AD}$ and other $\mathrm{ND}$ are still limited and do not stop the progression, but mainly control symptoms. Thus, targeting neuroinflammation represents one of the most promising disease-modifying treatments against ND.

Recently recognized for their powerful effect upon controlling inflammation, flavonoids have been largely studied as an alternative to treat inflammatory conditions. These compounds are derived from plant secondary metabolism and are widely distributed in the plant kingdom (Agati et al., 2011). They act by interfering with several intracellular processes, such as increasing the activation of antioxidant enzymes (Magalingam et al., 2013), additionally to the suppression of lipid peroxidation (Schinella et al., 2010) and inhibition of pro-inflammatory and proapoptotic mediators (Zhang et al., 2011; Raza et al., 2013). Studies suggest the correlation of dietary flavonoid consumption with the reduction of dementia levels (Beking and Vieira, 2010; Shahidi and Ambigaipalan, 2015; Terahara, 2015).

Apigenin (4,5,7-trihydroxyflavone) is a flavonoid belonging to the class of flavones, found in abundance in fruits and teas (McKay and Blumberg, 2006; Gazola et al., 2015). Studies have shown several biological activities associated with apigenin treatment, such as antioxidant (Han et al., 2012), anti-inflammatory (Lee et al., 2015), neurogenic (Souza et al., 2015), neuroprotective (Balez et al., 2016), and antitumor (Coelho et al., 2019). Importantly, apigenin can cross the bloodbrain barrier (Popović et al., 2014), which is of great significance to treat CNS disorders. However, despite studies have shown its diverse biological activities in different models, the mechanisms by which apigenin promotes neuroprotection remain elusive.

In this light, in this study, we used a well-established co-culture model of neurons and glial cells (Silva et al., 2013) to investigate the anti-inflammatory and neuroprotective activity of the flavonoid apigenin, in three different models of neuroinflammation induced by lipopolysaccharide (LPS; classic neuroinflammation), IL-1 $\beta$ or $A \beta$ oligomers. Overall, it was demonstrated that apigenin is not neurotoxic in the tested concentration and has neuroprotective potential, evidenced by the reduction of caspase 3 activation and the increase in neuronal viability, and this effect is thought to be mainly through the control of microglia and astrocyte inflammatory response. 


\section{MATERIALS AND METHODS}

\section{Neuron/Glial Cells Co-cultures}

Glial cells and neurons were obtained from the brain hemispheres of Wistar rats as described previously (Dos Santos Souza et al., 2018). The animals were provided by the Animal Facilities of the Department of Physiology of the Institute of Health Sciences of the Federal University of Bahia (Salvador, Brazil). All experiments were performed following the local Ethical Committee for Animal Experimentation of the Health Sciences Institute (CEUA, Protocol $n^{\circ}$ 027/2012). For the co-cultures, glial cells were obtained from the cortex of neonate animals, aged 1 to 2 days, and neurons were obtained from embryos with 14-16 day-old embryos (Figure 1). Cerebral hemispheres were removed aseptically. Meninges and blood vessels were removed from each cortex, and then the material was mechanically dissociated and filtered into a sterile $75 \mathrm{~mm}$ diameter Nitex membrane $\left(R \& D^{\circledR}\right)$. Dissociated cells were then cultured in DMEM HAM F12 medium (Gibco $\left.{ }^{\circledR}\right)$, supplemented with amino acids $(2 \mathrm{mM} \mathrm{L}$-glutamine and $0.011 \mathrm{~g} / \mathrm{l}$ pyruvate, Merck), 10\% fetal bovine serum (FBS, Gibco ${ }^{\circledR}$ ), 3.6 g/l Hepes (Merck), $33 \mathrm{mM}$ glucose (Cultilab, SP, Brazil), antibiotics (100 IU/ml penicillin $\mathrm{G}$ and $100 \mu \mathrm{g} / \mathrm{ml}$ streptomycin, Gibco ${ }^{\circledR}$ ), and cultured in $100-\mathrm{mm} \varnothing$ plates (TPP) in a humidified atmosphere with $5 \% \mathrm{CO}_{2}$ at $37^{\circ} \mathrm{C}$. The culture medium was changed every $48 \mathrm{~h}$ and cells were cultured for 15 days. Cells were then washed three times with PBS, detached with trypsin solution at $37^{\circ} \mathrm{C}$ (Trypsin/EDTA, Merck), plated at a density of $1 \times 10^{5}$ cell $/ \mathrm{cm}^{2}$ as described previously (Dos Santos Souza et al., 2018) and maintained in culture for $72 \mathrm{~h}$. After incubation, neurons obtained from cerebral hemispheres of 14- to 16-day-old Wistar rat embryos, using the same method described above for glial isolation, were suspended in supplemented DMEM/HAM F12 $\left(\right.$ Gibco $\left.^{\circledR}\right)$ and seeded at half the number of glial cells $\left(5 \times 10^{4}\right.$ cells $/ \mathrm{cm}^{2}$ ) onto the glial monolayer. The co-cultures were incubated in a humidified atmosphere with $5 \% \mathrm{CO}_{2}$ at $37^{\circ} \mathrm{C}$ for 8 days in vitro and the medium changed every $48 \mathrm{~h}$.

\section{Drugs and Treatments}

Flavonoid apigenin $\left(4^{\prime}, 5,7\right.$-trihydroxyflavone $)$ adopted in this work was purchased commercially (Sigma-Aldrich, St. Louis, MO, USA 97\% purity A3145). It was dissolved in dimethyl sulfoxide (DMSO, Sigma-Adrich, St. Louis, MO, USA) to a stock concentration of $100 \mathrm{mM}$ and kept protected from light at a temperature of $-20^{\circ} \mathrm{C}$. Final dilution was obtained at the time of treatment by diluting the concentrated solution directly into the culture medium. Cells were exposed to flavonoids at a final concentration of $1 \mu \mathrm{M}$. Control cultures were treated with DMSO in a volume equivalent to apigenin concentration $(0.01 \%)$. Experimental analyses were performed $24 \mathrm{~h}$ after the treatment. To induce inflammatory damage, co-cultured cells were exposed for $24 \mathrm{~h}$ to LPS $(1 \mu \mathrm{g} / \mathrm{ml}$, Sigma Chemical Company L2880) or Interleukin 1 beta (IL-1 $\beta, 10 \mathrm{ng} / \mathrm{ml}$; R\&D Systems 501-RL-010), or for $4 \mathrm{~h}$ to $\mathrm{A} \beta$ oligomers $(500 \mathrm{nM}$, American Peptide). The experimental design is illustrated in Figure 1. Final dilution of LPS and IL-1 $\beta$ was obtained at the time of treatment by diluting the stock solution directly into the culture medium. The concentration and exposure time adopted followed established protocols (Radesäter et al., 2003; Moraes et al., 2015). Solubilization of the $\beta$-amyloid peptide from synthetic A $\beta 1-42$ peptide (American Peptide) was performed according to protocol already established (De Felice et al., 2008; Lourenco et al., 2013), and was diluted in culture medium to obtain a $500 \mathrm{nM}$ solution from a stock solution $(100 \mu \mathrm{M})$. The concentration and exposure time adopted followed established protocols described in the literature (Lourenco et al., 2013). In brief, A $\beta 1-42$ peptide was solubilized at $1 \mathrm{mM}$ in ice-cold 1,1,1,3,3,3 hexafluoro-2-propanol (HFIP; Merck) and the resulting clear colorless solution was incubated at room temperature for $60 \mathrm{~min}$. The solution was then placed on ice for $10 \mathrm{~min}$ and aliquoted $(25 \mu \mathrm{l}$ of HFIP solution to obtain $0.133 \mathrm{mg} \mathrm{A} \beta$ ). Microtubes were left open in the laminar flow hood for $12 \mathrm{~h}$ for evaporation of HFIP. The complete elimination of HFIP was done by SpeedVac ${ }^{\circledR}$ centrifugation for $10 \mathrm{~min}$. Aliquots containing $A \beta$ films were stored at $-20^{\circ} \mathrm{C}$ for later use. $\mathrm{A} \beta$ oligomer preparations were made from $\mathrm{A} \beta$ films resuspended in $2 \%$ dimethylsulfoxide (DMSO; Sigma-Adrich, St. Louis, MO, USA) to obtain a solution at $5 \mathrm{mM}$. This solution was then diluted in $100 \mu \mathrm{M}$ sterile PBS and incubated at $4^{\circ} \mathrm{C}$ for $24 \mathrm{~h}$. After incubation, the preparation was centrifuged at $14,000 \mathrm{~g}$ for $10 \mathrm{~min}$ at $4^{\circ} \mathrm{C}$ to remove insoluble $\mathrm{A} \beta$ aggregates (fibrils). The centrifugation supernatant containing the oligomers was kept at $4^{\circ} \mathrm{C}$ until use. To determine the concentration of oligomers in the preparations, the BCA Kit (BIO-RAD) was used.

\section{Fluoro-Jade B Staining}

The neuroprotective potential of apigenin was assessed with the Fluoro-Jade B assay (FJB, Millipore, AG310). This staining was used to evaluate neuronal death. Cells were cultured in 96-well black bottom plates (Corning Incorporated, 3603) and treated as described. After treatments the co-culture, supernatants were removed and the cells were fixed with ethanol at $4^{\circ} \mathrm{C}$ for $10 \mathrm{~min}$, washed three times with PBS, and permeabilized with $0.3 \%$ Triton X-100 in PBS (Merck) for $10 \mathrm{~min}$. After this time, the cultures were washed three times with distilled water and incubated with $0.001 \%$ FJB solution for $30 \mathrm{~min}$ at room temperature (RT), under slow agitation and protected from the light. After incubation, the cells were washed three times with PBS and incubated for $5 \mathrm{~min}$ at RT in the dark with $5 \mu \mathrm{g} / \mathrm{ml}$ 4,6-diamidino-2-phenylindole (DAPI) for nuclear staining, and then washed three times with PBS. Analyses were performed on a spectrophotometer (Varioskan ${ }^{\mathrm{TM}}$ Flash Multimode Reader, Thermo Plate), and the fluorescence intensity of each sample was measured at $480 \mathrm{~nm}$ for FJB and $350 \mathrm{~nm}$ for DAPI. The value of absorbance of FJB of each well was normalized to the DAPI absorbance in the same well. Three independent experiments were performed. Thereafter, cells were analyzed using a fluorescence microscope (Leica, DFC7000). Quantification was analyzed with ImageJ $1.33 \mathrm{u}$.

\section{Rosenfeld's Staining}

Glial and neuronal morphological changes in response to inflammatory stimuli and treatment with apigenin were primarily assessed by Rosenfeld's staining. After exposure of the 


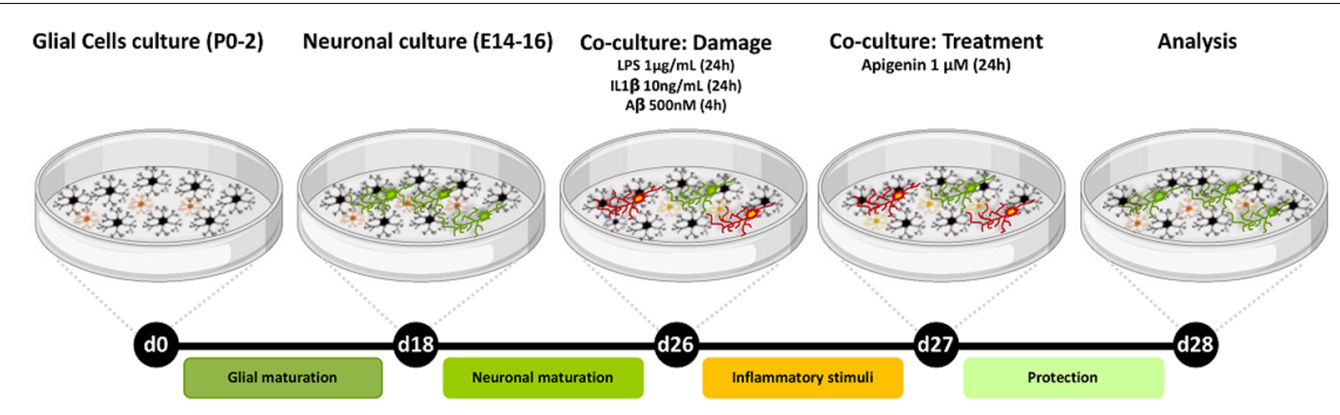

FIGURE 1 | Experimental design. Neurons/glia co-cultures were obtained from the cortex of Wistar rats. After 26 days of cultivation, the cultures were treated with either A $\beta$ oligomers $(500 \mathrm{nM})$ for $4 \mathrm{~h}$ or $\mathrm{LL}-1 \beta(10 \mathrm{ng} / \mathrm{ml})$ or LPS $(1 \mu \mathrm{g} / \mathrm{ml})$ for $24 \mathrm{~h}$ and then treated with apigenin $(1 \mu \mathrm{M})$ and analyzed after $24 \mathrm{~h}$ treatments.

cells to the treatments, the culture medium was discarded and the cells were washed three times with phosphate-buffered saline (PBS, Sigma) and then fixed in 4\% paraformaldehyde for $20 \mathrm{~min}$ at room temperature (RT), after that, cultures were washed three times with PBS. Fixed cells were stained by the protocol established by Rosenfeld (Rosenfeld, 1947). Rosenfeld's reagent was added and incubated for $20 \mathrm{~min}$ at room temperature. Three independent experiments were performed. Thereafter, the plates were rinsed with water, air-dried, analyzed in an optic phase microscope (Nikon; Figures 2A,C).

\section{Immunocytochemistry}

Glial and neuronal response to inflammatory stimuli and treatment with apigenin was assessed by immunocytochemistry using the following primary antibodies: anti- $\beta$-Tubulin III (mouse, 1:500; BioLegend, 801202), anti-GFAP (rabbit, 1:300; DAKO, Z0334), anti-Iba-1 (ionized calcium-binding adaptor molecule 1; rabbit, 1:200; Wako, 019-19741), anti-CD68 (rat, 1:100; Abcam, ab53444), anti-active caspase-3 (rabbit, 1:300; Chemicon, ab3623), anti-CD11b/c (OX42; mouse, Abcam, ab1211), anti-IL-6 (rabbit, 1:500; Abcam, ab6672) and anti-gp130 (rabbit, 1:500; Abcam, ab6672). After exposure of the cells to the treatments, the culture medium was discarded and the cells were washed three times with phosphate-buffered saline (PBS, Sigma) and then fixed in $4 \%$ paraformaldehyde for $20 \mathrm{~min}$ at room temperature (RT). After that cultures were washed three times with PBS and permeabilized with Triton X-100 $(0.3 \%)$ in PBS for $15 \mathrm{~min}$ and then washed again with PBS three times for $5 \mathrm{~min}$. After this time, non-specific binding sites were blocked by incubation with PBS containing 5\% bovine serum albumin (BSA; Sigma-Adrich, St. Louis, MO, USA) for $1 \mathrm{~h}$. After blocking, samples were incubated with primary antibodies diluted in PBS containing $1 \%$ of BSA in a humid chamber at $4^{\circ} \mathrm{C}$ for $12 \mathrm{~h}$. Subsequently, cells were washed three times with PBS and incubated with secondary antibodies diluted in PBS containing $1 \%$ of BSA and kept under slow agitation for $1 \mathrm{~h}$ at RT, protected from the light. The cells were washed with PBS three times and incubated with $5.0 \mu \mathrm{g} / \mathrm{ml}$ 4,6-diamidino-2-phenylindole (DAPI, Molecular Probes, Eugene, OR, USA) for nuclear staining for. The cell coverslips were then washed three times in PBS and mounted on slides containing $80 \%$ glycerol $\mathrm{N}$-propyl gallate mounting medium (Sigma-Adrich, St. Louis, MO, USA). Staining was visualized on a fluorescence microscope (Leica, DFC7000) and (Leica, SP8 confocal). Images were captured with a $20 \times$ or $40 \times$ objective. Three independent experiments were performed. Quantification was analyzed with ImageJ $1.33 \mathrm{u}$. The following secondary antibodies were used at the indicated dilutions: Alexa Fluor 488-conjugated goat anti-mouse IgG (1:500; Molecular Probes, A11001), Alexa Fluor 594-conjugated goat anti-rabbit IgG (1:500; Molecular Probes, A11012), Alexa Fluor 488 goat anti-rabbit IgG [H\&L] (1:500; Molecular Probes A11008), Alexa Fluor 555-conjugated goat anti-rat IgG (1:500; Molecular Probes, A21434) and Alexa Fluor 594-conjugated goat anti-rabbit IgG (1:500, Molecular Probes A11012). The quantification was performed by analyzing the total number of positive cells (per marker), divided by the total number of nuclei (DAPI positive) $\times 100$.

\section{Bromodeoxyuridine Cell Proliferation Assay}

To evaluated proliferation was using the Bromodeoxyuridine (BrdU) cell proliferation assay (Sigma-Aldrich, Inc., St. Louis, MO, USA). BrdU (10 $\mu \mathrm{M})$ was added to the wells since each treatment had started. Cells were incubated for $2 \mathrm{~h}$ in a humidified atmosphere of $95 \%$ air and $5 \% \mathrm{CO}_{2}$ at $37^{\circ} \mathrm{C}$. Cells were fixed and DNA was denatured by treatment with denaturing solution $(2 \mathrm{~N} \mathrm{HCl})$ for $20 \mathrm{~min}$ at room temperature. Anti-BrdU monoclonal antibody (mouse, 1:200, Sigma-Adrich, St. Louis, MO, USA B8434) diluted in PBS was pipetted into the wells and allowed to incubate for $1 \mathrm{~h}$. Unbound antibody was washed away and cells were incubated with Alexa Fluor 546-conjugated goat anti-mouse IgG (1:500; Molecular Probes, A11003), diluted in PBS-T for $1 \mathrm{~h}$ under slow agitation at room temperature. After incubation, the cell nuclei were stained with DAPI $(5 \mu \mathrm{g} / \mathrm{ml})$ for $10 \mathrm{~min}$ at room temperature. All reagents were used following the manufacturer's instructions. Experiments were performed in triplicate. Thereafter, cells were analyzed using a fluorescence microscope (Leica, DFC7000) Quantification was analyzed with ImageJ 1.33 u software (Wayne Rasband, National Institutes of Health, Bethesda, MD, USA). 

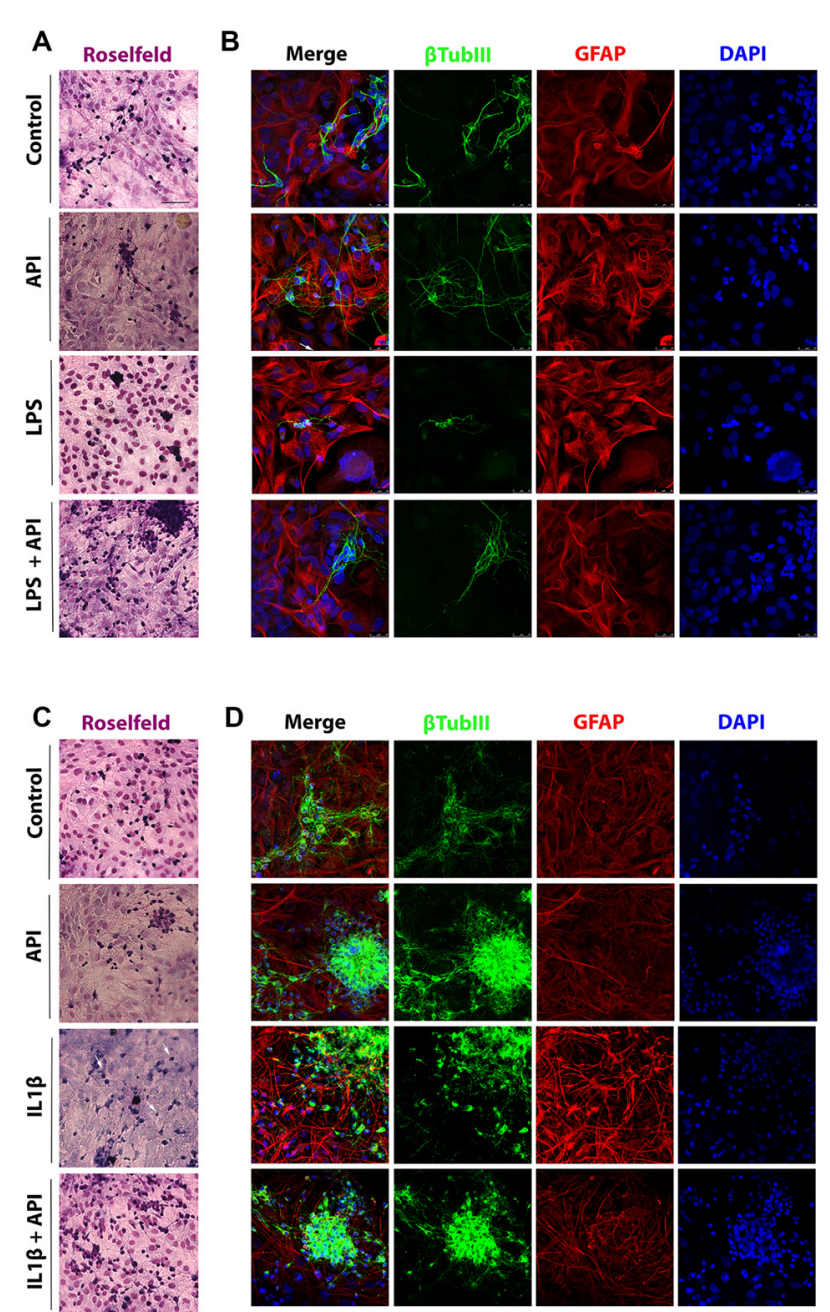

FIGURE 2 | Apigenin preserves neuronal and astrocyte morphology. Effects of apigenin (API, $1 \mu \mathrm{M}$ ) treatment on the integrity of neurons and astrocyte

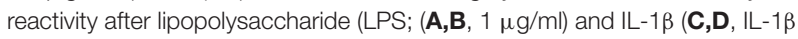
$10 \mathrm{ng} / \mathrm{ml}$ ) inflammatory stimuli. Morphological changes were primarily assessed by analyzing the Rosenfeld's staining $(\mathbf{A}, \mathbf{C})$. The patterns of expression of the cytoskeletal protein $\beta$-tubulin III ( $\beta$-tublll, green) specific of neurons, and the cytoskeletal protein GFAP (red) marker of astrocyte morphology and reactivity were determined by immunocytochemistry and confocal analysis after $24 \mathrm{~h}$ treatments; control cultures were treated with dimethyl sulfoxide (DMSO; 0.01\%) and nuclear chromatin was stained with 4,6-diamidino-2-phenylindole (DAPI; blue). Obj. 40x, scale bar: $50 \mu \mathrm{m}$; white arrows indicate neurons without neurites.

\section{Quantitative RT-PCR}

To evaluate gene expression for proteins of interest, after the treatment period, the culture medium was removed and then total RNA was extracted with Trizol ${ }^{\circledR}$ reagent (Invitrogen, Life Technologies, 15596026). Extraction was performed according to the manufacturer's specifications. Total RNA purity and concentration were determined by spectrophotometric analysis using KASVI Nano Spectrum (cat\# K23-0002). DNA contaminants were removed by treating the RNA samples with DNase using the Ambion DNA-free kit (cat\# AM1906, Life Technologies ${ }^{\mathrm{TM}}$ ). For
cDNA synthesis, SuperScript ${ }^{\circledR} \quad$ VILO $^{\text {TM MasterMix }}$ (cat\# MAN0004286, Invitrogen ${ }^{\mathrm{TM}}$, Life Technologies) was used in a $20-\mu \mathrm{l}$ reaction with a concentration of $2.5 \mu \mathrm{g}$ of total RNA, following the manufacturer's instructions. Quantitative real-time PCR (qPCR) was performed using Taqman ${ }^{\circledR}$ Gene Expression Assays (Applied Biosystems, Foster City, CA, USA) containing two primers to amplify the sequence of interest, a specific Taqman ${ }^{\circledR}$ MGB probe and TaqMan Universal Master Mix II with UNG (cat\# 4440038 Invitrogen, Life Technologies ${ }^{\mathrm{TM}}$ ). The assays corresponding to the genes quantified in this study were IL-1 $\beta$ (Rn00580432_m1), IL-6 (Rn01410330_m1), CCL5 (Rn00579590_m1), IL-10 (Rn00563409_m1), brainderived neurotrophic factor (BDNF; Rn02531962_s1), and NTF4 (Rn00566076_s1). Real-time PCR was performed using the Quant Studio 7 Flex $^{\mathrm{TM}}$ Real Time PCR System (Applied Biosystems, CA, USA). The thermocycling conditions were performed according to the manufacturer's specifications. The actin beta (Actb; Rn00667869_m1) and hypoxanthine phosphoribosyltransferase 1 (HPRT1; Rn01527840_m1) targets were used as reference genes (endogenous controls) for normalization of gene expression data. Data were analyzed using the $2^{-\Delta \Delta C t}$ method. The results represent the average of three independent experiments.

\section{Statistical Analyses}

The results were analyzed by the GraphPad Prism 5, statistical program (CA, USA). It was analyzed whether the values came from a Gaussian distribution. To determine the statistical difference between the groups, we performed one-way analysis of variance (ANOVA) followed by Student-Newman-Keuls post-test for normal samples. For non-normal samples, an analysis was performed using Kruskal-Wallis followed by Dunn's post-test. Confidence intervals were defined at a $95 \%$ confidence level ( $p<0.05$ was considered to be statistically significant). Fold change was calculated by dividing the average (mean) value of the experimental group by that of the control group. In all figures, error bars represent SEM of at least three independent experiments.

\section{RESULTS}

\section{Apigenin Preserves Neuron and Astrocyte Morphology After LPS and IL-1 $\beta$-Induced Inflammatory Stimuli}

LPS a component of the gram-negative bacteria cell membrane, is known to be a potent inducer of the inflammatory response via toll-like receptor 4 (Park and Lee, 2013; Xu et al., 2017) and according to Jin et al. (2017), the IL-1 $\beta$ is a proinflammatory cytokine that plays a key role in the initiation and development of a complex cellular inflammatory cascade. Excessive IL-1 $\beta$ production in the CNS, mainly by glial cells, is associated with neuroinflammation found in neurodegenerative processes. Here, we investigate the effects of flavonoid apigenin against classical neuroinflammation produced by LPS and against inflammatory damage produced by cytokine IL- $1 \beta$ in glia/neurons co-cultures in terms of preservation of neuronal integrity, modulation of 
glial (astrocyte and microglia) activation and inflammatory signaling (Figure 2). Glial and neuronal Morphological changes in response to inflammatory stimuli and treatment with apigenin were primarily assessed by Rosenfeld's staining a differential stain used to differentiate nuclear and cytoplasmic morphology (Figures 2A,C). We observed that in control conditions $(0.01 \%$ DMSO), the glial cells represented by light pink cytoplasm and dark pink big nucleus, the cells look diffused with a polygonal shape. On the other hand, neurons are represented by a dark purple cytoplasm with neurites represented by long and fine purple processes. We do not observe morphological changes in cells treated with apigenin when compared with control cells. However, we observed a reduction in the neurites in the neurons after the treatment with LPS (Figure 2A). On the other hand, apigenin was able to rescue the neuronal integrity after LPS treatment. Similar results were observed after the treatment with IL-1 $\beta$, where we can observe a reduction in the neurites induced by IL- $1 \beta$ and a rescue for apigenin (Figure $2 \mathrm{C}$ ).

To evaluate the effect of apigenin treatment on neurons integrity after $24 \mathrm{~h}$ treatment with LPS or with IL-1 $\beta$, immunostaining was performed for $\beta$-tubulin III ( $\beta$-tubIII) a standard neuronal marker in association with GFAP, a classical marker of astrocyte reactivity. We observed that apigenin treatment $(1 \mu \mathrm{M}$; Figures 2B,D) preserved the neurites network, maintained neuronal cell body integrity and typical astrocyte polygonal morphology, similar to the control condition $(0.01 \%$ DMSO). After induction of inflammatory stimulus with LPS $(1 \mu \mathrm{g} / \mathrm{ml})$, the neurites network was not preserved, and only perinuclear staining was observed, associated with cell bodies forming irregular clustering (Figure 2B). Also, astrocytes showed reactive morphology, characterized by the presence of longer processes with higher GFAP expression (Figure 2B). However, in cultures treated with apigenin after LPS damage astrocyte maintained the non-reactive phenotype (similar to that observed under control conditions and after apigenin treatment) and the neurons integrity was preserved, as well as their networks of interconnections, compared to cultures treated with LPS alone.

The effects of apigenin on the integrity of neurons and astrocytes were confirmed in co-cultures submitted to IL-1 $\beta$ induced neuroinflammation (Figure 2D). After induction of IL-1 $\beta$ stimulus $(10 \mathrm{ng} / \mathrm{ml})$, few cells labeled for $\beta$ tubIII were observed when compared to the control cultures. Also, it was verified in astrocytes the emission of cellular processes with high immunoreactivity to GFAP, characteristic of reactive astrocytes. However, apigenin treatment after IL- $1 \beta$ damage was able to maintain the entire neurite network, increase the intensity of the $\beta$ tubIII labeling with neuron cluster formation, and preserve the astrocyte morphology similar to that observed in the control conditions (Figure 2D).

\section{Apigenin Protects Neurons Against LPS and IL-1 $\beta$-Induced Inflammatory Stimuli}

To better characterize the neuroprotective potential of apigenin against neuroinflammation, glia/neurons were exposed to LPS $(1 \mu \mathrm{g} / \mathrm{ml})$ or IL-1 $\beta(10 \mathrm{ng} / \mathrm{ml})$ for $24 \mathrm{~h}$ and then treated with apigenin $(1 \mu \mathrm{M})$ for additional $24 \mathrm{~h}$, and then labeled with Fluor Jade-B (FJB) that marks neurons in degeneration (Figures 3A,B).
Apigenin treatment did not change neuronal viability when compared to control cultures (0.01\% DMSO). On the other hand, induction of damage by LPS led to neuronal degeneration, with an increase of $0.61 \pm 0.14$ in the relative fluorescence intensity (IRF) compared to control. It was observed that after LPS damage, apigenin treatment reduced IRF to baseline levels observed in the control condition, also demonstrating its neuroprotective potential (Figures $3 \mathbf{A}, \mathbf{B}$ ).

To verify the neuroprotective potential of apigenin against neuroinflammation, immunocytochemistry evaluation of the presence of active caspase-3 a classical apoptosis marker in association with $\beta$-tubulin III ( $\beta$ tubIII) was performed (Figures 3C-H). The induction of damage by LPS promoted caspase- 3 activation in $1.6 \pm 0.1 \%$ of total cells, and $15.8 \pm 3.7 \%$ of BtubIII positive neurons (Figures 3C-E). This increase was significant compared to the control $[0.3 \pm 0.08 \%$ and $3.4 \pm 1.1 \%$, respectively (Figures $3 \mathrm{C}-\mathbf{E}$ )]. On the other hand, after LPS damage, apigenin treatment significantly reduced the proportion of caspase- 3 positive cells $(0.4 \pm 0.09 \%)$ and caspase-3/ 3 tubIII positive neurons $(3.7 \pm 0.7 \%)$ when compared to cultures treated with LPS alone, and no difference was observed between this group and the control group. IL$1 \beta$ treatment promoted caspase- 3 activation in $1.7 \pm 0.1 \%$ of total cells and $7.6 \pm 1.7 \%$ of $\beta$ tubIII positive neurons compared to control cultures $(0.7 \pm 0.2 \%$ and $2.3 \pm 1.0 \%$, respectively; Figures 3F-H). However, apigenin treatment after IL- $1 \beta$ damage reduced the percentage of caspase- 3 positive cells $(0.3 \pm 0.03 \%)$ and double-labeled neurons for caspase- 3 and $\beta$ tubIII $(1.0 \pm 0,4 \%)$ when compared to cultures treated with IL-1 $\beta$ alone. Moreover, treatment with $1 \mu \mathrm{M}$ apigenin did not induce caspase- 3 activation compared to control (DMSO $0.01 \%$ ). These data suggest that apigenin does not induce cell death in glia/neurons co-cultures and disrupts the progression of apoptosis in a neuroinflammation model. Together these findings demonstrate the neuroprotective and glial modulatory potential of the flavonoid in conditions of inflammatory stimuli and neuronal damage.

\section{Apigenin Modulates Microglial Activation Profile After Inflammatory Stimuli}

To evaluate if the neuroprotective effect of apigenin after different inflammatory stimuli is associated with microglial activation, first immunostaining was performed for Iba1 , a classic structural marker of microglia in co-cultures to characterize changes on morphology, and in association with BrdU immunostaining, to characterize microglia in proliferation. After induction of damage by LPS $(1 \mu \mathrm{g} / \mathrm{ml})$, the percentage of Iba-1 and BrdU positive cells increased $(41.5 \pm 4 \%)$ compared to the control $(21.4 \pm 3.2 \%)$, which characterizes microglial proliferation (Figures 4A,B). However, apigenin treatment after LPS damage significantly reduced the percentage of positive Iba-1 and BrdU cells $(9.4 \pm 2.8 \%)$ when compared to co-cultures treated with LPS alone and did not show statistical significance in the percentage of these cells when compared to control. Moreover, apigenin treatment $(1 \mu \mathrm{M})$ had no significant effect on the proportion 


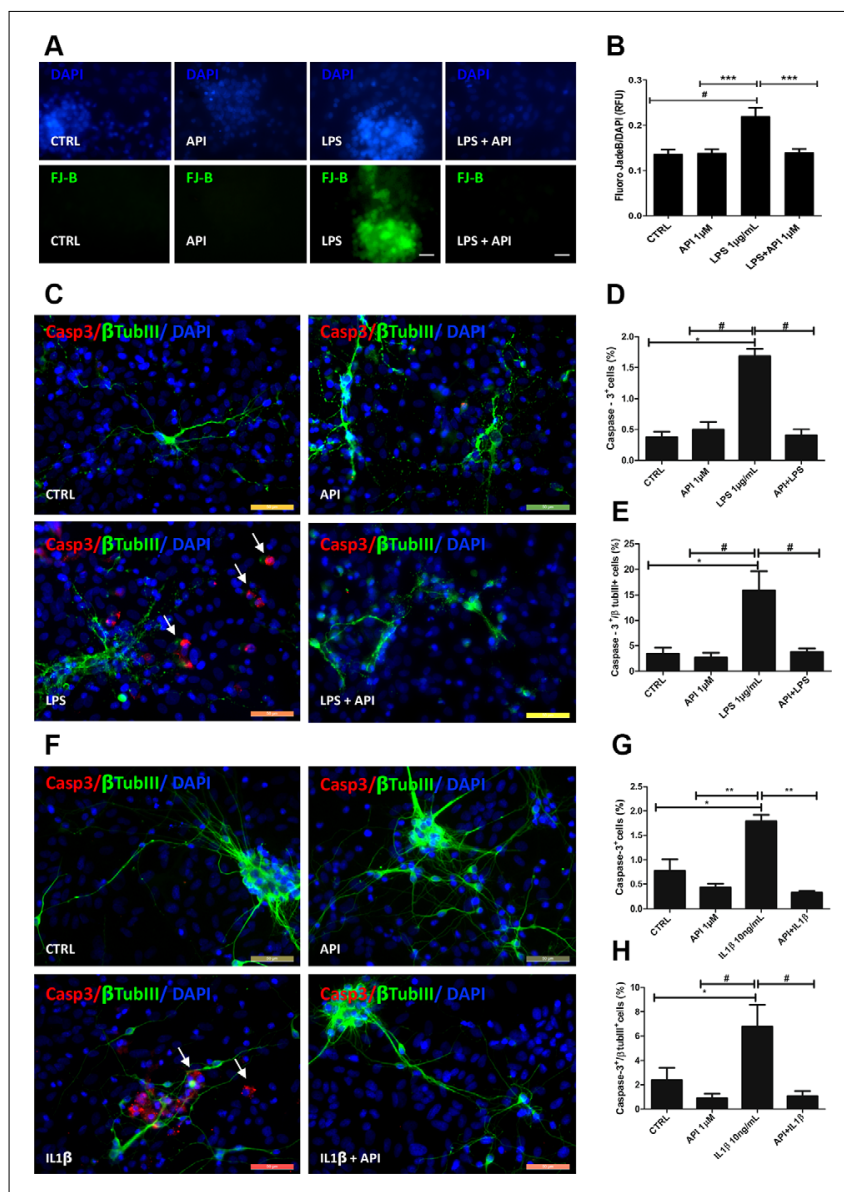

FIGURE 3 | Apigenin protects neurons against neuroinflammation induced by LPS and IL-1 $\beta$. Effects of apigenin (API, $1 \mu \mathrm{M}$ ) treatment on the integrity of neurons and induction of apoptosis after lipopolysaccharide (LPS) (A-E, 1 $\mu \mathrm{g} / \mathrm{ml})$ or IL-1 $\beta$ (F-H, $10 \mathrm{ng} / \mathrm{ml})$ inflammatory stimuli. (A) Evaluation of neuronal degeneration by FJB assay in cultures after LPS $(1 \mu \mathrm{g} / \mathrm{ml})$ inflammatory stimuli. (B) Graph Barr showing neuronal degeneration by Fluoro-Jade B (FJB) assay. (C,F) The patterns of expression of the cytoskeletal protein $\beta$-tubulin III ( $\beta$-tublll, green) specific of neurons, and of the activated caspase-3 (CASP, red), a marker of cells in apoptosis, were determined by immunocytochemistry after $24 \mathrm{~h}$ treatments. Control cultures were treated with DMSO (0.01\%) and nuclear chromatin was stained with DAPI (blue). (D,G,E,H) Graphs represent the total population of caspase-3 positive cells, and the population of cells doubly labeled $\beta$ Tublll and caspase-3; *statistical significance concerning control (DMSO 0.01\%), $p$-value $<0.01$; " statistical significance in relation to the group treated with LPS, $p$-value $<0.01$; ${ }^{* *}$ and " statistical significance in relation to the group treated with IL-1 $\beta p$-value $<0.001$ and $p$-value $<0.01$; Statistical test: analysis of variance (ANOVA) followed by Student Newman-Keuls test; results expressed as mean \pm standard deviation of FJB fluorescence intensity; " represents statistical difference compared to control DMSO 0.01\%) with $p$-value $<0.001^{\star \star \star}$ represents statistical difference compared to the group treated with LPS with $p$-value $<0.001$. Values are expressed as the mean $\pm \operatorname{SEM}(n=3)$ and were tested for significance by ANOVA followed by the Newman-Keuls test. Obj. 40x, scale bar: $50 \mu \mathrm{m}$; arrows indicate cells doubly labeled $\beta$ Tublll and caspase-3.

of double-labeled cells for Iba-1 and BrdU compared to control co-cultures.

Modulation of the microglial profile was also evaluated based on the morphological changes visualized by the Iba-1 protein immunostaining. We verified that under control conditions treated with $0.01 \%$ DMSO, the microglia presented branched morphology. Exposure to LPS ( $1 \mu \mathrm{g} / \mathrm{ml}$; Figure 4A), was able to induce phenotypic changes. It was observed that in these conditions, Iba-1 positive cells showed ameboid morphology. However, microglia morphology in co-cultures treated with apigenin after inflammatory stimuli presented a morphological pattern similar to that observed in the control conditions, showing branched morphology.

Moreover, to evaluate the effects of apigenin on the modulation of the microglial profile after inflammatory stimuli with LPS $(1 \mu \mathrm{g} / \mathrm{ml})$, double immunostaining was performed for Iba-1 protein and CD68, a specific M1 profile marker in glia/neurons co-cultures (Figure 4C). After exposure to LPS, an increase in the proportion of Iba-1 positive cells $(16.2 \pm 2.6 \%$; Figure 4D) and CD68 positive microglia (19 $\pm 4.1 \%)$ was observed compared to the control cultures $(8.6 \pm 0.9 \%$ and $3.6 \pm 1.9 \%$, respectively; Figure 4E). On the other hand, apigenin $(1 \mu \mathrm{M})$ treatment after LPS damage reduced significantly the percentage of Iba- 1 positive cells $(7.1 \pm 0.6 \%)$ and CD68 positive cells $(5.2 \pm 1.9 \%)$ when compared to cultures treated with LPS only (Figures 4C,E). No significant effect on the proportion of microglia and expression of the M1 marker was observed after apigenin treatment.

To confirm if the neuroprotective effect of apigenin after different inflammatory stimuli is associated with microglial activation, we stimulated the cells with IL-1 $\beta$ and then with apigenin. Similarly to LPS the treatment with IL-1 $\beta(10 \mathrm{ng} / \mathrm{ml})$, was able to induce phenotypic changes in microglial cells (Figure 4F) evidenced by the ameboid morphology of Iba-1 positive cells. However, microglia morphology in co-cultures treated with apigenin after inflammatory stimuli induced by IL-1 $\beta(10 \mathrm{ng} / \mathrm{ml})$, presented morphological pattern similar to that observed in the control conditions, showing branched morphology (Figure 4F). These results demonstrate that apigenin reduced microglial proliferation/activation after the inflammatory stimulus and reaffirm its anti-inflammatory effect.

\section{Apigenin Regulates the Expression of Inflammatory Mediators in Neurons/Glial Cells Co-cultures Submitted to IL-1 $\beta$ or LPS Stimulus}

To better characterize the anti-inflammatory effect of apigenin, co-cultures were exposed to IL-1 $\beta$ (10 ng/ml) for $24 \mathrm{~h}$ and then treated with apigenin $(1 \mu \mathrm{M})$. After treatments, the mRNA expression levels of the interleukin 6 (IL-6), C-C chemokine ligand 5 (CCL5) and IL-1 $\beta$ pro-inflammatory mediators, the IL-10 regulatory cytokine, the BDNF and neurotrophin-4 (NTF4) were evaluated by RT-qPCR (Figure 5). After IL-1 $\beta$ damage induction, there was an increase in IL6 , CCL5, and IL-1 $\beta$ mRNA expression when compared to control (Figures 5A-C). After IL-1 $\beta$ damage followed by apigenin treatment, a reduction in IL-6 levels, when compared to cultures treated with IL-1 $\beta$ alone (Figure 5A). Although apigenin treatment induced a reduction in CCL5 and IL-1 $\beta$ gene expression, it was not significant when compared to 

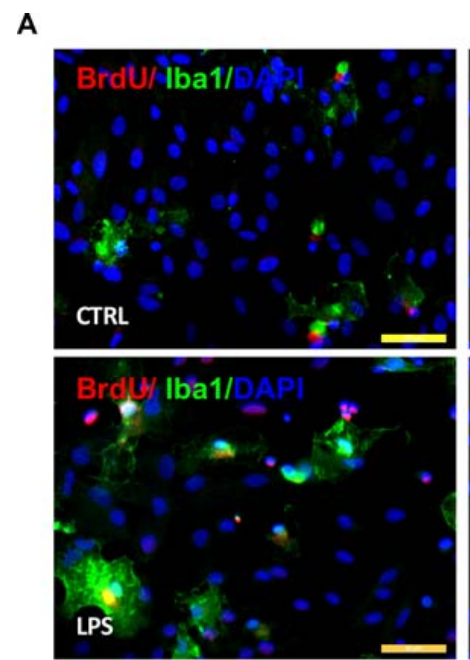

C
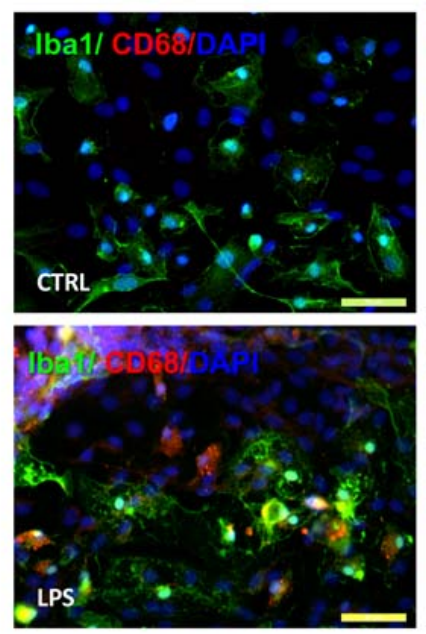

F

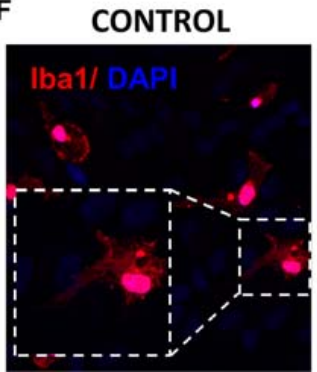

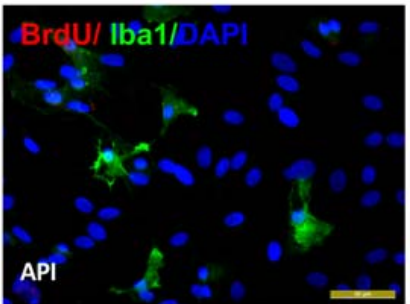
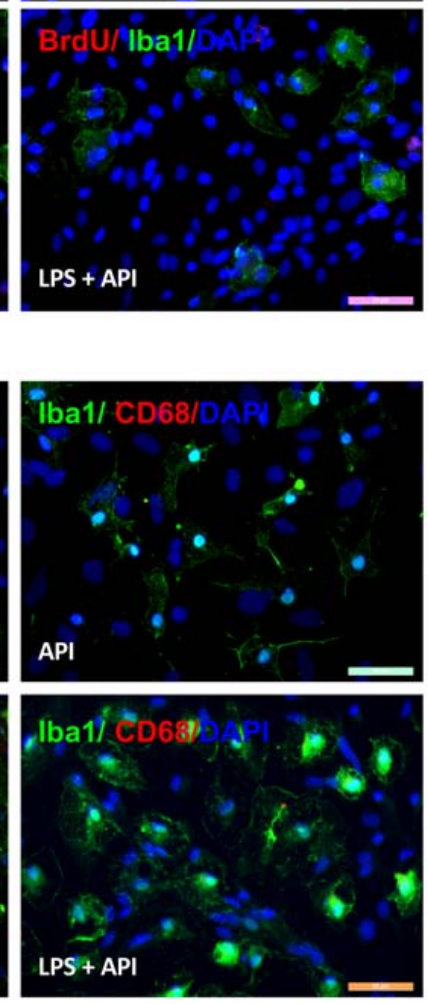

API

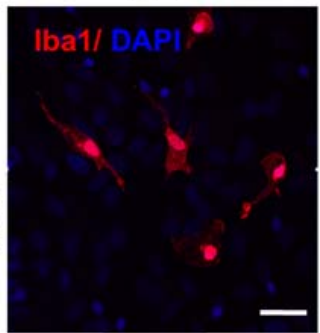

IL1 $\beta$
B

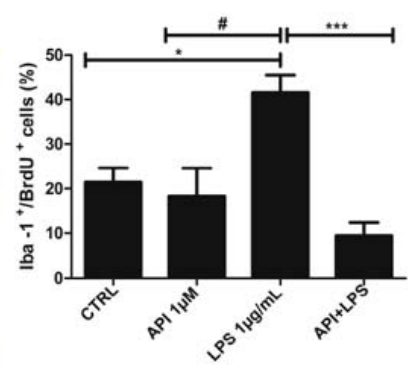

D

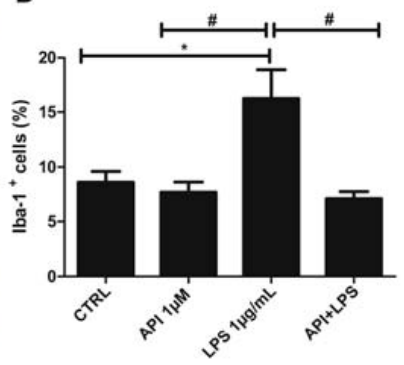

E
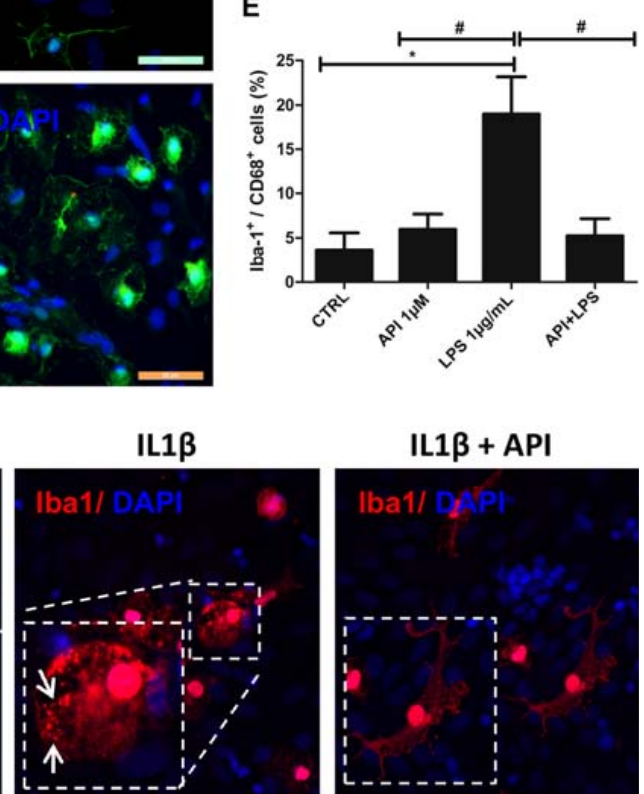

$\mathrm{IL} 1 \beta$ + API

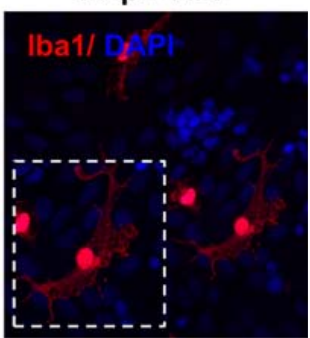

FIGURE 4 | Apigenin modulates microglial activation profile. Effects of apigenin (API, $1 \mu \mathrm{M})$ treatment on the activation of microglia after LPS (A-E, $1 \mu \mathrm{g} / \mathrm{ml})$, or $\mathrm{IL}-1 \beta(\mathbf{F}, 10 \mathrm{ng} / \mathrm{ml})$ inflammatory stimuli in glia/neurons co-cultures. Proliferation and changes in morphology, both features of microglial activation were analyzed. $(\mathbf{A}, \mathbf{B})$ Immunocytochemistry for ionized calcium-binding adapter molecule 1 (Iba-1, green), specific of microglia, associated with bromodeoxyuridine (BrdU; red), that marker cells in proliferation was performed in cultures submitted to inflammatory stimuli with LPS. Graphs (B,D) represents cell population labeled for both Iba-1 and BrdU; data a represented as mean of percentage \pm standard deviation of immunofluorescence labeling of Iba-1 and BrdU cells (C) Immunocytochemistry for Iba-1 (green), associated with CD68 (red), marker of activated microglia/macrophages in a proinflammatory profile was performed after $24 \mathrm{~h}$ treatments. (D,E) The graphs represent the total population of Iba-1 positive cells (microglia) and the population of double-labeled Iba-1 +/CD68 + microglia. (F) Immunocytochemistry for the cytoskeletal protein Iba-1 (red), was also performed in cultures submitted to inflammatory stimuli with IL-1 $\beta$; control cultures were treated with DMSO (0.01\%) and nuclear chromatin was stained with DAPI (blue); Obj. 40×, scale bar: $50 \mu \mathrm{m}$.; ${ }^{\star}$ represents statistical significance in relation to the control (DMSO 0.01\%) with $p$-value < 0.01; " represents statistically significant difference compared to the group treated with LPS, with $p$-value $<0.01$ and ${ }^{\star * \star}$ represents statistical significance in relation to the group treated with LPS, with $p$-value $<0.001$. Values are expressed as the mean \pm SEM $(n=3)$ and were tested for significance by ANOVA followed by the Newman-Keuls test; arrows indicate lba-1 positive cells showed ameboid morphology. 


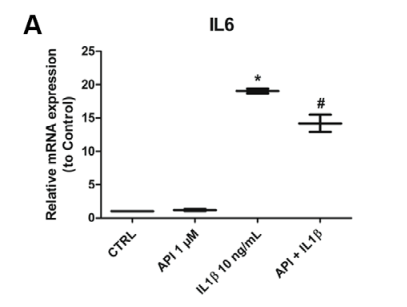

B

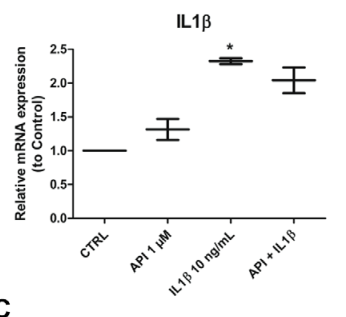

C

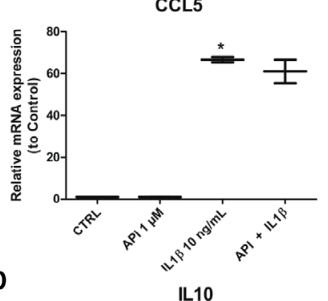

IL10

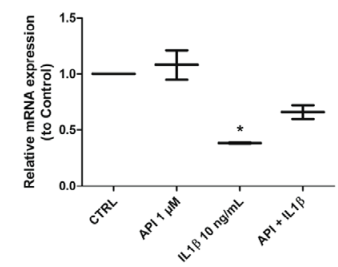

E

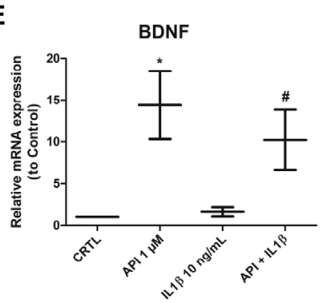

F

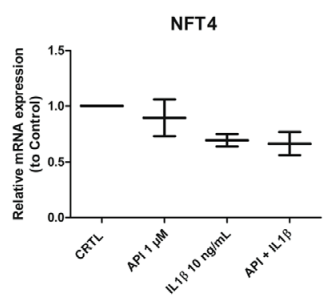

G
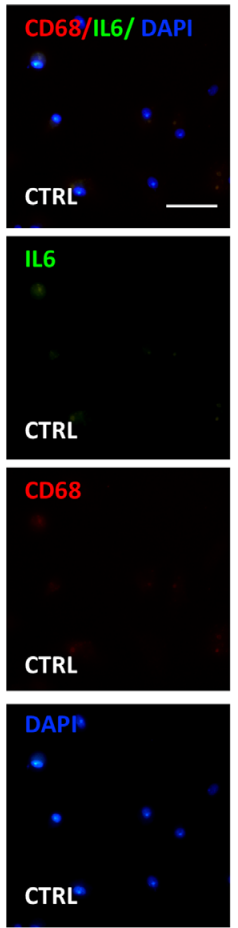

H

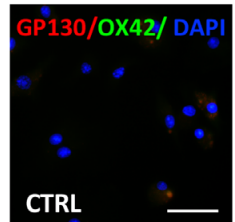

GP130

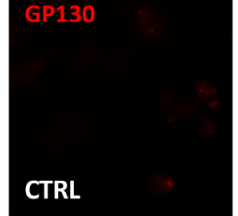

OX42

CTRL

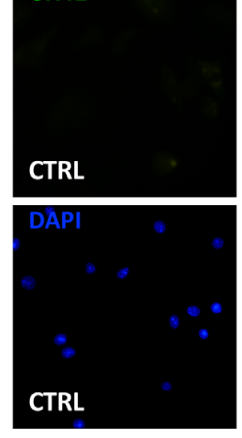

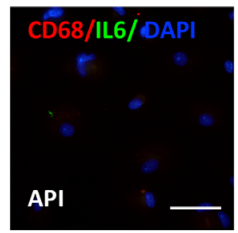

IL6

API
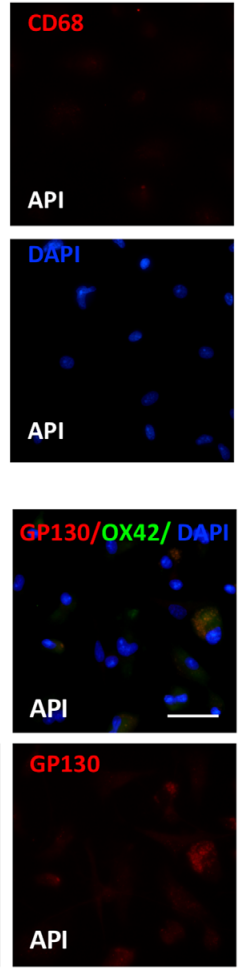

\section{OX42}
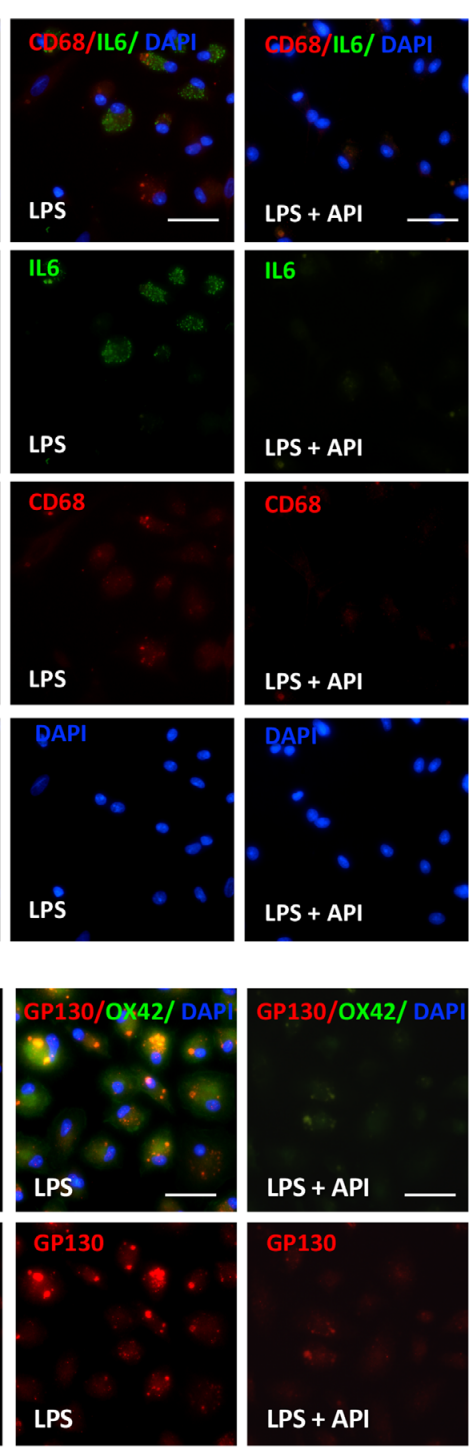

GP130
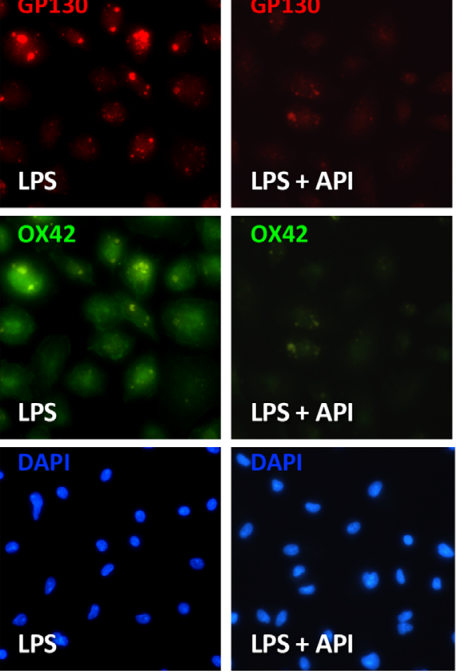

FIGURE 5 | Apigenin regulates the expression of inflammatory mediators. Effects of apigenin (API, $1 \mu \mathrm{M}$ ) treatment on expression of inflammatory and neurotrophic factors by qRT-PCR in glia/neurons co-cultures treated with IL-1 $\beta$ (10 ng/ml). (A-F) mRNA expression for proinflammatory (IL-6, IL-1 $\beta$ ) and regulatory interleukins (IL-10), for chemokine CCL5, for the brain-derived neurotrophic factor (BDNF) and neurotrophin-4 (NTF-4) were evaluated $24 \mathrm{~h}$ after treatment with apigenin. Effects of apigenin (API, $1 \mu \mathrm{M}$ ) treatment on expression of inflammatory markers by immunocytochemistry in glia/neurons co-cultures treated with LPS (1 $\mu \mathrm{g} / \mathrm{ml})$. (G) Immunocytochemistry for IL-6 (green), associated with CD68 (red), marker of activated microglia/macrophages in a proinflammatory profile. (H)

Immunocytochemistry for OX42 (green), associated with gp130 (red), marker of activated microglia/macrophages in a proinflammatory profile. Data were presented as a median of the relative expression to control cultures *statistical significance in relation to the control (DMSO $0.01 \%), p$-value $<0.01$; ${ }^{*}$ statistical significance in relation to the group treated with IL-1 $\beta, p$-value $<0.01$. Were tested for significance using the Kruskal-Wallis test followed by Dunn's test. 
cultures treated with IL-1 $\beta$ alone (Figures 5B,C). It was also observed a reduction in IL-10 expression after IL-1 $\beta$ treatment, when compared to the control (Figure 5D), and although apigenin treatment induced an increase in IL10 expression levels, it was not significant when compared to cultures treated with IL-1 $\beta$ alone. Moreover, in co-cultures treated only with apigenin the mRNA expression for both pro-inflammatory and regulatory factors was not changed. Furthermore, it was observed that apigenin was able to increase BDNF mRNA expression (14.4) when compared to control with DMSO (0.01\%; 1.0; Figure 5E). Our results revealed that apigenin was able to induce increase BDNF mRNA levels in neuronal and glial cell cocultures after damage with IL-1 $\beta$ (10.22) when compared to the IL-1 $\beta$-treated group and the control condition (Figure 5E). Neurotrophin NTF4 levels were also evaluated but did not show alterations between groups (Figure 5F). Since IL-1 $\beta$ induces microglial activation and increases IL- 6 mRNA expression, we investigated the direct effect of apigenin on inflammatory markers expression in neurons/glial cells co-cultures submitted to LPS stimulus. Immunofluorescence for CD68 (microglial M1 pro-inflammatory marker) and IL-6 (pro-inflammatory cytokine, M1 marker), OX42 (microglial activation marker) and Glycoprotein 130 (gp130), a type 1 cytokine receptor that is within the IL-6 receptor family), showed that inflammatory stimuli increased OX42, IL-6 and gp130 positive cells, which was abolished by apigenin treatment (Figures 5G,H).

\section{Apigenin Protects Neurons and Reduces Astrocyte and Microglial Activation Induced by Amyloid- $\beta$}

Neuroinflammation in the brain is a feature in $\mathrm{AD}$, this chronic inflammation is mainly attributed to microglial activation and the release of numerous inflammatory mediators (Kinney et al., 2018). We investigated if apigenin can protect neurons against $\mathrm{A} \beta$ toxicity and if it reduces microglia and astrocyte activation. After induction of damage with $\mathrm{A} \beta$ (500 nM), the labeling for $\beta$ tubIII was scarce and the astrocytes showed prolongations with high GFAP immunoreactivity, also suggesting glial reactivity (Figure 6A). However, apigenin treatment after $A \beta$ induced damage was able to increase the intensity of $\beta$ tubIII labeling with the formation of neural clusters and preserved astrocyte morphology and GFAP expression, patterns similar to control cultures (Figure 6A). Apigenin treatment alone did not affect $\beta$ tubIII expression in neurons and on GFAP expression and astrocyte morphology. Evaluation of microglial proliferation in co-cultures of neurons and glial cells exposed to $A \beta$ oligomers (500 nM) for $4 \mathrm{~h}$ and analyzed after additional $24 \mathrm{~h}$ demonstrated that $\mathrm{A} \beta$ damage promoted microglial proliferation, with an increase in the percentage of Iba- 1 and BrdU positive cells $(33.7 \pm 7.7 \%)$ compared to the control $(12 \pm 2 \%$; Figures $6 \mathrm{~B}, \mathrm{C})$. However, apigenin treatment after $\mathrm{A} \beta$ damage significantly reduced the percentage of positive Iba-1 and BrdU cells when compared to co-cultures treated with $A \beta$ alone and did not show statistical significance in the percentage of these cells when compared to control. Moreover, apigenin

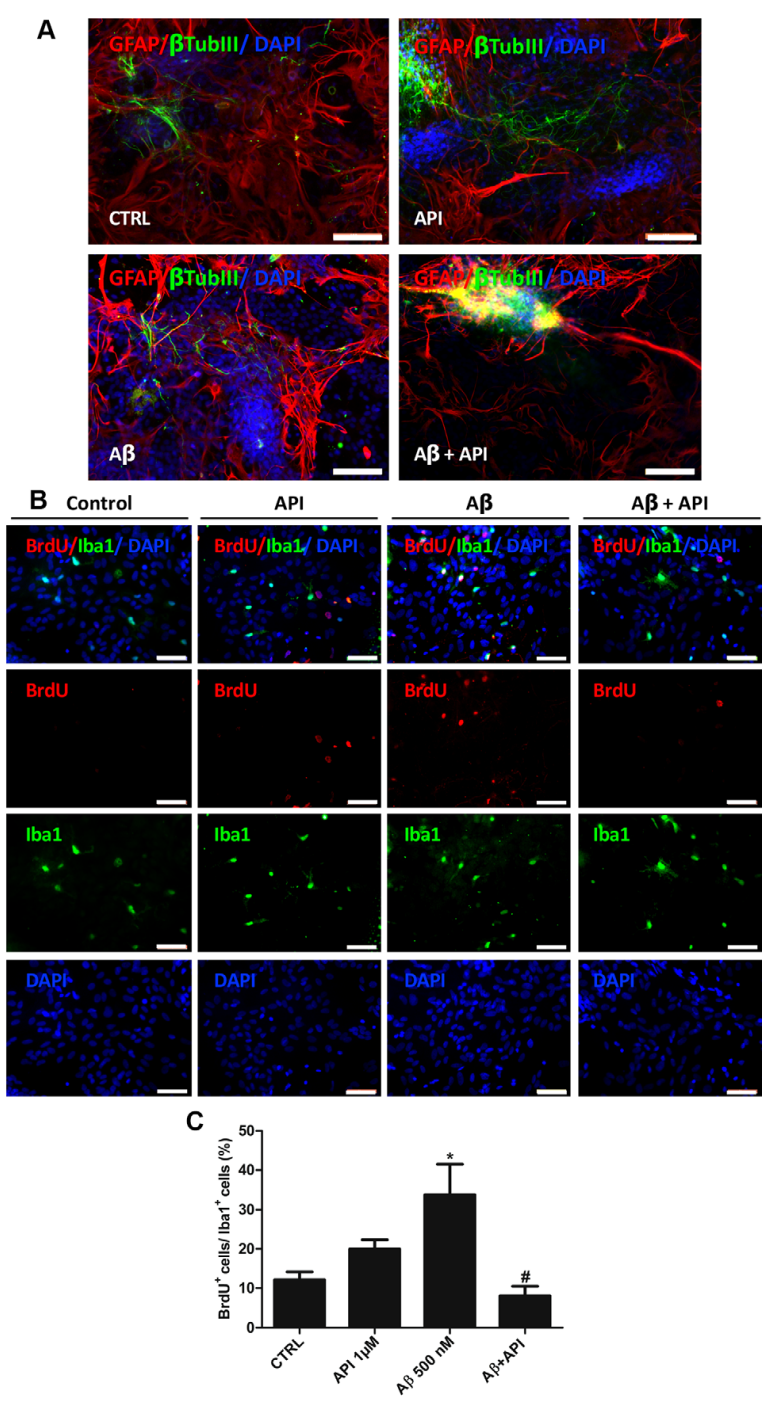

FIGURE 6 | Apigenin protects neurons and reduces glial activation induced by amyloid- $\beta$. Effects of apigenin (API, $1 \mu \mathrm{M})$ treatment on the integrity of neurons and glial reactivity after $A \beta(500 \mathrm{nM})$ exposure. (A) The patterns of expression of the cytoskeletal protein $\beta$-tubulin III ( $\beta$-tublll, green) specific of neurons, and the cytoskeletal protein GFAP (red) marker of astrocyte morphology and reactivity were determined by immunocytochemistry analysis after $24 \mathrm{~h}$ treatments; control cultures were treated with DMSO $(0.01 \%)$ and nuclear chromatin was stained with DAPI (blue). Obj. 20×, scale bar: $100 \mu \mathrm{m}$. (B) Immunocytochemistry for ionized calcium-binding adapter molecule 1 (Iba-1, green), specific of microglia, associated with BrdU (red), that marker cells in proliferation was performed in cultures submitted to $A \beta$. Obj. 40×, scale bar: $50 \mu \mathrm{m}$. (C) Graph represents cell population labeled for both Iba-1 and BrdU; data are presented as mean of percentage \pm standard deviation of immunofluorescence labeling of lba- 1 and BrdU cells. *represents statistical significance in relation to the control (DMSO 0.01\%) with

$p$-value $<0.05$; " represents statistically significant difference compared to the group treated with $A \beta$, with $p$-value $<0.01$. Values are expressed as the mean $\pm \operatorname{SEM}(n=3)$ and were tested for significance by ANOVA followed by the Newman-Keuls test.

treatment $(1 \mu \mathrm{M})$ had no significant effect on the proportion of double-labeled cells for Iba-1 and BrdU compared to control co-cultures. 


\section{DISCUSSION}

Many in vitro models of CNS studies have been developed to elucidate the mechanisms associated with insults that lead to neuron death, and thus find better therapeutic targets against neurodegenerative diseases associated with neuroinflammation. Among these models, we highlight the co-culture of neuron and glia, which has several advantages, especially because it is a method that uses high cell density, which may favor the generation of neuronal phenotypes that actively interact with glial cells and mimic tissue-like biological conditions (Al-Ali et al., 2017).

In this study, we used as experimental model co-cultures of neurons and glial cells already well established in our group (Silva et al., 2013) to investigate the anti-inflammatory and neuroprotective potential of flavonoid apigenin in three different inflammatory models: induced by LPS (classical neuroinflammation), IL- $1 \beta$ or $A \beta$ oligomers. In this work, we demonstrate that apigenin is not neurotoxic at the concentration tested and has neuroprotective potential, evidenced by the decreased number of caspase- $3^{+}$cells and increased neuronal viability. In a previous study, we tested the apigenin $(10 \mu \mathrm{M})$ activity on embryonic and human-induced pluripotent stem cells (hPSC). Our data showed that apigenin induced neural differentiation and promote synaptogenesis (Souza et al., 2015). Furthermore, in an animal model of spinal cord injury, it was observed that apigenin treatment $(10$ and $20 \mathrm{mg} / \mathrm{kg}$; via ip) recovered neuronal function, and neuroprotective effect associated with antiapoptotic effects, with reduced caspase 3 expression and an increased ratio of $\mathrm{Bcl}-2 / \mathrm{Bax}$ genes (Zhang et al., 2014).

In $\mathrm{AD}$, evidences suggest that persistent activation of microglia and astrocytes, initially triggered by $A \beta$ oligomers, triggers a chronic inflammatory response that is partly characterized by the exacerbated production of proinflammatory cytokines. In turn, these cytokines perpetuated neuroinflammation and glial activation and consequently contributed to the progression of neurodegeneration (Stewart et al., 2010; Heneka et al., 2015). These data support the hypothesis that the use of anti-inflammatory agents may slow the progression of this pathology (Daniels et al., 2016). In this sense, apigenin deserves prominence within the group of plant-derived polyphenolic compounds, as it demonstrates anti-inflammatory and neuroprotective potential, presenting itself as a promising compound for the treatment of neurodegenerative diseases, such as AD (Balez et al., 2016; Anusha et al., 2017).

Different CNS stimuli may induce activation, proliferation, and changes in the morphology and function of microglia, which can be modulated by anti-inflammatory agents, such as flavone luteolin, which has been shown to promote change in LPS-exposed BV2 microglial cell lines, from amebic morphology to branched morphology. This change in morphology has also been associated with inhibition of NO synthesis and IL-6 mRNA expression, favoring the M2 phenotype with anti-inflammatory and neuroprotective characteristics (Dirscherl et al., 2010). The findings found in this article were similar to this study, considering that the activation state and the microglia phenotype may be reflected by its cellular form (Vinet et al., 2012; Tang and Le, 2016), we show that apigenin it acts as a potent modulator of the microglial profile since, after induced inflammatory response, apigenin treatment generated morphological change from the ameboid state to branched microglia.

Dynamic changes in microglial phenotypes are associated with neurodegenerative diseases, and the dichotomy of the M1/M2 microglial profile is widely accepted, where such microglia can perform proinflammatory (M1) or anti-inflammatory (M2) functions (Tang and Le, 2016). As already described, LPS (Kobayashi et al., 2013) and A $\beta$ oligomers (Maezawa et al., 2011; Shi et al., 2017; Taipa et al., 2017) are potent inducers of microglia activation, characterized by proliferation and polarization of the M1 microglial profile, characterized by expression of NFKB and CD68 markers. In this study, it was observed that apigenin was able to decrease the percentage of CD68 and BrdU positive (proliferating) microglia, as well as reduced the protein levels of IL6, OX42 and the gp130 (Type 1 cytokine receptor) after inflammatory stimuli.

Like microglial cells, astrocytes respond to CNS injury, play an important role in neuroinflammation, homeostasis impairment, and synaptic dysfunction observed in AD (Verkhratsky et al., 2010). As described by Ledo et al. (2013), intracerebroventricular injection of $\mathrm{A} \beta$ oligomers in mice induces an increase in astrocyte reactivity with increased expression of GFAP in the hippocampus and cortex of these animals and increased levels of proinflammatory cytokines. In the present study, the different inflammatory stimuli induced changes in astrocyte morphology. However, after treatment with apigenin, no morphological characteristics of astrogliosis were visualized. The present study reaffirms the immunomodulatory potential of apigenin and the reduction of IL- $1 \beta$-induced neuroinflammation, observed through the downregulation of mRNA expression and protein levels of IL-6 a proinflammatory cytokine. Associated with the reduction of IL- 6 we also observed a reduction in the protein levels of gp130, identified as the $\beta$ subunit of the IL-6R complex. Thus, gp130-related cytokine plays an integral role in inflammation (Jones et al., 2011). Similarly, Zhang X. et al. (2014) demonstrated that apigenin $(6.25,12.5$ and 25 $\mu \mathrm{M})$ was able to inhibit the production of IL-6, IL-1 $\beta$, and CCL5 by human (THP-1) and mouse (J774A.1) macrophages activated by LPS $(100 \mathrm{ng} / \mathrm{ml})$ by modulating intracellular signaling pathways as mitogen-activated protein kinase (MAPK), suppressing ERK1/2 phosphorylation and blocking NF- $\kappa \mathrm{B}$ activation. The same authors revealed that apigenin suppressed IL-1 $\beta$ production by blocking the activation of caspase- 1 and disrupting assembly of the NLRP3 inflammasome complex. Also, they observed that the downregulation of IL-10 by LPS was reversed by apigenin, suggesting that flavonoids may modulate the inflammatory response through multiple mechanisms.

According to Tong et al. (2008), IL-1 $\beta$ interferes with BDNF signaling by suppressing the activation of signal transduction pathways (PI3-K/Akt and MAPK/ERK) that is associated with neuronal survival. Thus, IL-1 $\beta$ makes neurons vulnerable to degeneration by interfering with 
BDNF-induced neuroprotection. This neurotrophin also plays a critical role in the pathophysiology of $\mathrm{AD}$, in which neuroinflammation is observed, and partly characterized by increased pro-inflammatory cytokines such as IL-1 $\beta$. Zhang C. et al. (2014) showed that the deregulation of BDNF signaling pathways correlates with synaptic loss and cellular dysfunction underlying cognitive impairment in AD. Our results revealed that apigenin was able to induce increase BDNF mRNA levels in neuronal and glial cell co-cultures after damage with IL-1 $\beta$. These findings reaffirm the neuroprotective effect of apigenin, as described by Zhao et al. (2013) which demonstrated increased BDNF levels and the restoration of learning deficits and cognitive function in apigenin-treated 2xTg-AD rats.

Taken together, our data suggest that apigenin at a concentration of $1 \mu \mathrm{M}$ has neuroprotective and anti-inflammatory potential demonstrated in different inflammatory models. Exacerbated inflammatory response to different stimuli was observed, which was characterized by the expression of high levels of proinflammatory cytokines and chemokines, microglial proliferation, polarization to M1 microglial profile and astrogliosis. Therefore, we suggest that this neuroinflammation led to neurodegeneration, which was attenuated by increased BDNF levels and modulation of the inflammatory response as a consequence of apigenin treatment. Finally, this is the first report of the interaction of flavonoid apigenin in the co-culture of neurons and glial cells subjected to IL-1 $\beta$ damage, correlating with $\mathrm{AD}$. In the studies developed by Choi et al. (2014), no neuroprotective effect of apigenin was observed at $30 \mu \mathrm{M}$ concentration in in vitro model of $\mathrm{AD}$ using $A \beta(25-35)$ at a concentration of $20 \mu \mathrm{M}$. However, in this work, we demonstrated that apigenin in a lower concentration had a neuroprotective and anti-inflammatory effect in different neuroinflammation models.

Evidence indicates that IL-1 $\beta$ expression is one of the most important neuropathological factors in $\mathrm{ND}$, such as $\mathrm{AD}$, being recognized as a central factor in neuroinflammation (Azizi and Mirshafiey, 2012; Xie et al., 2015). Second (Halle et al., 2008) the activation of the NLRP3 inflammasome is closely associated with caspase 1 activation and IL- $1 \beta$ release by $A \beta$-exposed microglia. In a more recent study (Dempsey et al., 2017) analyzed the effect of small NLRP3 inhibitor molecules called MCC950 on microglia cultures. MCC950 inhibited caspase- 1 activation, stimulated A $\beta$ phagocytosis and reduced IL-1 $\beta$ expression in vitro. The same study demonstrated, an in vivo model using $2 \mathrm{xTg}-\mathrm{AD}$ mice, that MCC950 (10 mg/kg) also inhibited NLRP3 and microglial activation as well as reduced $A \beta$ accumulation. Together, these data suggest that $A \beta$ accumulation may be mediated by the formation of the inflammasome complex and induction of IL-1 $\beta$.

Thus, the search for new drugs aimed at blocking the exacerbated formation of this complex and attenuating neuroinflammation may prove to be a valuable strategy in the treatment of $\mathrm{ND}$, including $\mathrm{AD}$. Thus, this work is a pioneer in demonstrating the influence of apigenin on the protection against deleterious effects induced by IL-1 $\beta$ in co-cultures of neurons and glial cells.

\section{CONCLUSION}

We have shown that apigenin presents neuroprotective and neuroimmunomodulatory effects in in vitro models of neuroinflammation. Thus, might represent a potential agent for the treatment of neurodegenerative conditions.

\section{DATA AVAILABILITY STATEMENT}

All datasets generated for this study are included in the article.

\section{ETHICS STATEMENT}

The animal study was reviewed and approved by Ethical Committee for Animal Experimentation of the Health Sciences Institute (CEUA, Protocol n ${ }^{\circ}$ 027/2012).

\section{AUTHOR CONTRIBUTIONS}

ND performed all experimentation, analyzed, interpreted the data and was a major contributor in writing the manuscript. CS, MA, and ABS helped with the maintenance of the cell culture and, additionally, ABS, MA, and BS helped to perform and analyze RT-qPCR. ADA, JS, and DS designed and performed experiments to obtain $\mathrm{A} \beta$ oligomers. MC, VS, BS, ADA, DS, and CS revised it critically for intellectual content. CS, AB, and SC designed the experiments, supervised the study, edited and reviewed the manuscript. All authors read and approved the final manuscript.

\section{FUNDING}

This work was supported by the Coordination of Personnel Improvement of Higher Level (Coordenação de Aperfeiçoamento de Pessoal de Nível Superior; CAPES, Process $\mathrm{N}^{\circ}$ 88881.117666/2016-01, MPhil fellowship to ND, PNPD fellowship to CS-Processes 001), Foundation for Research Support of the State of Bahia (Fundação de Amparo à Pesquisa do Estado da Bahia; Processes $\mathrm{N}^{\circ}$ RED0016/2013; INT 0016/2016) and the National Council for Scientific and Technological Development (Conselho Nacional de Desenvolvimento Científico e Tecnológico; CNPq, MCTI/CNPq/EU-14/2014 Process 443723/2014-1; INCTs).

\section{ACKNOWLEDGMENTS}

We would like to thank the Postgraduate Program in Immunology of the Federal University of Bahia and the Laboratory of Neurochemistry and Cell Biology for the support. This study was presented during the XIV European Meeting on Glial Cells in Health and Disease 2019 in Porto (Proceedings for Glia Porto 2019; https://onlinelibrary.wiley.com/doi/abs/10. 1002/glia.23675). 


\section{REFERENCES}

Agati, G., Biricolti, S., Guidi, L., Ferrini, F., Fini, A., Tattini, M., et al. (2011). The biosynthesis of flavonoids is enhanced similarly by UV radiation and root zone salinity in L. vulgare leaves. J. Plant Physiol. 168, 204-212. doi: 10.1016/j.jplph. 2010.07.016

Al-Ali, H., Beckerman, S. R., Bixby, J. L., and Lemmon, V. P. (2017). In vitro models of axon regeneration. Exp. Neurol. 287, 423-434. doi: 10.1016/j. expneurol.2016.01.020

Alasmari, F., Alshammari, MA., Alasmari, AF., Alanazi, W. A., and Alhazzani, K. (2018). Neuroinflammatory Cytokines induce amyloid $\beta$ neurotoxicity through modulating amyloid precursor protein levels/metabolism. Biomed. Res. Int. 8:3087475. doi: 10.1155/2018/3087475

Allen, N. J., and Barres, B. A. (2009). Neuroscience: Glia-more than just brain glue. Nature 457, 675-677. doi: 10.1038/457675a

Anusha, C., Sumathi, T., and Joseph, L. D. (2017). Protective role of apigenin on rotenone induced rat model of Parkinson's disease: suppression of neuroinflammation and oxidative stress mediated apoptosis. Chem. Biol. Interact. 269, 67-79. doi: 10.1016/j.cbi.2017. 03.016

Azizi, G., and Mirshafiey, A. (2012). The potential role of proinflammatory and antiinflammatory cytokines in Alzheimer disease pathogenesis. Immunopharmacol. Immunotoxicol. 34, 881-895. doi: 10.3109/08923973. 2012.705292

Balez, R., Steiner, N., Engel, M., Muñoz, S. S., Lum, J. S., Wu, Y., et al. (2016). Neuroprotective effects of apigenin against inflammation, neuronal excitability and apoptosis in an induced pluripotent stem cell model of Alzheimer's disease. Sci. Rep. 6:31450. doi: 10.1038/srep31450

Beking, K., and Vieira, A. (2010). Flavonoid intake and disability-adjusted life years due to Alzheimer's and related dementias: a population-based study involving twenty-three developed countries. Public Health Nutr. 13, 1403-1409. doi: 10.1017/S1368980009992990

Burda, J. E., and Sofroniew, M. V. (2014). Reactive gliosis and the multicellular response to CNS damage and disease. Neuron 81, 229-248. doi: 10.1016/j. neuron.2013.12.034

Choi, S. M., Kim, B. C., Cho, Y. H., Choi, K. H., Chang, J., Park, M. S., et al. (2014). Effects of flavonoid compounds on $\beta$-amyloid-peptide-induced neuronal death in cultured mouse cortical neurons. Chonnam Med. J. 50, 45-51. doi: 10.4068/cmj.2014.50.2.45

Coelho, P. L. C., Amparo, J. A. O., da Silva, A. B., da Silva, K. C., Braga-de-Souza, S., Barbosa, P. R., et al. (2019). Apigenin from croton betulaster Müll restores the immune profile of microglia against glioma cells. Phytother. Res. 33, 3191-3202. doi: 10.1002/ptr.6491

Daniels, M. J., Rivers-Auty, J., Schilling, T., Spencer, N. G., Watremez, W., Fasolino, V., et al. (2016). Fenamate NSAIDs inhibit the NLRP3 inflammasome and protect against Alzheimer's disease in rodent models. Nat. Commun. 7:12504. doi: 10.1038/ncomms 12504

De Felice, F. G., Wu, D., Lambert, M. P., Fernandez, S. J., Velasco, P. T., Lacor, P. N., et al. (2008). Alzheimer's disease-type neuronal tau hyperphosphorylation induced by A $\beta$ oligomers. Neurobiol. Aging 29, 1334-1347. doi: 10.1016/j.neurobiolaging.2007.02.029

Dempsey, C., Rubio Araiz, A., Bryson, K. J., Finucane, O., Larkin, C., Mills, E. L., et al. (2017). Inhibiting the NLRP3 inflammasome with MCC950 promotes non-phlogistic clearance of amyloid- $\beta$ and cognitive function in APP/PS1 mice. Brain. Behav Immun. 61, 306-316. doi: 10.1016/j.bbi.2016. 12.014

Dirscherl, K., Karlstetter, M., Ebert, S., Kraus, D., Hlawatsch, J., Walczak, Y., et al. (2010). Luteolin triggers global changes in the microglial transcriptome leading to a unique anti-inflammatory and neuroprotective phenotype. J. Neuroinflammation 7:3. doi: 10.1186/1742-2094-7-3

Dos Santos Souza, C., Grangeiro, M. S., Lima Pereira, E. P., Dos Santos, C. C., da Silva, A. B., Sampaio, G. P., et al. (2018). Agathisflavone, a flavonoid derived from Poincianella pyramidalis (Tul.), enhances neuronal population and protects against glutamate excitotoxicity. Neurotoxicology 65, 85-97. doi: 10.1016/j.neuro.2018.02.001

Doty, K. R., Guillot-Sestier, M. V., and Town, T. (2015). The role of the immune system in neurodegenerative disorders: adaptive or maladaptive? Brain Res. 1617, 155-173. doi: 10.1016/j.brainres.2014.09.008
Gazola, A. C., Costa, G. M., Castellanos, L., Ramos, F. A., Reginatto, F. H., Lima, T. C. M., et al. (2015). Involvement of GABAergic pathway in the sedative activity of apigenin, the main flavonoid from Passiflora quadrangularis pericarp. Rev. Bras. Farmacogn. 25, 158-163. doi: 10.1016/j.bjp.2015.03.009

Ghadery, C., Koshimori, Y., Coakeley, S., Harris, M., Rusjan, P., Kim, J., et al. (2017). Microglial activation in Parkinson's disease using $\left[{ }^{18} \mathrm{~F}\right]$-FEPPA. J. Neuroinflammation 14:8. doi: 10.1186/s12974-016-0778-1

Halle, A., Hornung, V., Petzold, G. C., Stewart, C. R., Monks, B. G., Reinheckel, T., et al. (2008). The NALP3 inflammasome is involved in the innate immune response to amyloid- $\beta$. Nat. Immunol. 9, 857-865. doi: 10.1038/ni.1636

Han, J. Y., Ahn, S. Y., Kim, C. S., Yoo, S. K., Kim, S. K., Kim, H. C., et al. (2012). Protection of apigenin against kainate-induced excitotoxicity by anti-oxidative effects. Biol. Pharm. Bull. 35, 1440-1446. doi: 10.1248/bpb.b110686

Heneka, M. T., Carson, M. J., El Khoury, J., Landreth, G. E., Brosseron, F., Feinstein, D. L., et al. (2015). Neuroinflammation in Alzheimer's disease. Lancet Neurol. 14, 388-405. doi: 10.1016/S1474-4422(15)70016-5

Jara, J. H., Gautam, M., Kocak, N., Xie, E. F., Mao, Q., Bigio, E. H., et al. (2019). MCP1-CCR2 and neuroinflammation in the ALS motor cortex with TDP-43 pathology. J. Neuroinflammation 16:196. doi: 10.1186/s12974-0191589-y

Jin, L., Ding, M., Oklopcic, A., Aghdasi, B., Xiao, L., Li, Z., et al. (2017). Nanoparticle fullerol alleviates radiculopathy via NLRP3 inflammasome and neuropeptides. Nanomedicine 13, 2049-2059. doi: 10.1016/j.nano.2017.03.015

Jones, S. A., Scheller, J., and Rose-John, S. (2011). Therapeutic strategies for the clinical blockade of IL-6/gp130 signaling. J. Clin. Invest. 121, 3375-3383. doi: 10.1172/JCI57158

Kinney, J. W., Bemiller, S. M., Murtishaw, A. S., Leisgang. A, M., Salazar, A. M., and Lamb, B. T. (2018). Inflammation as a central mechanism in Alzheimer's disease. Alzheimers Dement. 4, 575-590. doi: 10.1016/j.trci.2018.06.014

Kobayashi, K., Imagama, S., Ohgomori, T., Hirano, K., Uchimura, K., Sakamoto, K., et al. (2013). Minocycline selectively inhibits M1 polarization of microglia. Cell Death Dis. 4:e525. doi: 10.1038/cddis.2013.54

Kraft, A. D., and Harry, G. J. (2011). Features of microglia and neuroinflammation relevant to environmental exposure and neurotoxicity. Int. J. Environ. Res Public Health 8, 2980-3018. doi: 10.3390/ijerph8072980

Ledo, J. H., Azevedo, E. P., Clarke, J. R., Ribeiro, F. C., Figueiredo, C. P., Foguel, D., et al. (2013). Amyloid- $\beta$ oligomers link depressive-like behavior and cognitive deficits in mice. Mol. Psychiatry 18, 1053-1054. doi: 10.1038/mp.2012.168

Lee, J. A., Ha, S. K., Cho, E., and Choi, I. (2015). Resveratrol as a bioenhancer to improve anti-inflammatory activities of apigenin. Nutrients 7, 9650-9661. doi: $10.3390 /$ nu7115485

Lourenco, M. V., Clarke, J. R., Frozza, R. L., Bomfim, T. R., Forny-Germano, L., Batista, A. F., et al. (2013). TNF- $\alpha$ mediates PKR-dependent memory impairment and brain IRS-1 inhibition induced by Alzheimer's $\beta$-amyloid oligomers in mice and monkeys. Cell Metab. 18, 831-843. doi: 10.1016/j.cmet. 2013.11.002

Maezawa, I., Zimin, P. I., Wulff, H., and Jin, L. W. (2011). Amyloid- $\beta$ protein oligomer at low nanomolar concentrations activates microglia and induces microglial neurotoxicity. J. Biol. Chem. 286, 3693-3706. doi: 10.1074/jbc.M110. 135244

Magalingam, K. B., Radhakrishnan, A., and Haleagrahara, N. (2013). Rutin, a bioflavonoid antioxidant protects rat pheochromocytoma (PC-12) cells against 6-hydroxydopamine (6-OHDA)-induced neurotoxicity. Int. J. Mol. Med. 32, 235-240. doi: 10.3892/ijmm.2013.1375

McCauley, M. E., and Baloh, R. H. (2019). Inflammation in ALS/FTD pathogenesis. Acta Neuropathol. 137, 715-730. doi: 10.1007/s00401-0181933-9

McKay, D. L., and Blumberg, J. B. (2006). A review of the bioactivity and potential health benefits of chamomile tea (Matricaria recutita L.). Phytother. Res. 20 , 519-530. doi: 10.1002/ptr.1900

Moraes, C. A., Santos, G., de Sampaio e Spohr, T. C., D’Avila, J. C., Lima, F. R., Benjamim, C. F., et al. (2015). Activated microglia-induced deficits in excitatory synapses through IL-1 $\beta$ : implications for cognitive impairment in sepsis. Mol. Neurobiol. 52, 653-663. doi: 10.1007/s12035-014-8868-5

Park, B. S., and Lee, J. O. (2013). Recognition of lipopolysaccharide pattern by TLR4 complexes. Exp. Mol. Med. 45:e66. doi: 10.1038/emm.2013.97

Popović, M., Caballero-Bleda, M., Benavente-García, O., and Castillo, J. (2014). The flavonoid apigenin delays forgetting of passive avoidance 
conditioning in rats. J. Psychopharmacol. 28, 498-501. doi: 10.1177/0269881113 512040

Procaccini, C., Santopaolo, M., Faicchia, D., Colamatteo, A., Formisano, L., de Candia, P., et al. (2016). Role of metabolism in neurodegenerative disorders. Metabolism 65, 1376-1390. doi: 10.1016/j.metabol.2016. 05.018

Radesäter, A. C., Johansson, S., Oberg, C., and Luthman, J. (2003). The vitamin-E analog trolox and the NMDA antagonist MK-801 protect pyramidal neurons in hippocampal slice cultures from IL-1 $\beta$-induced neurodegeneration. Neurotox. Res. 5, 433-442. doi: 10.1007/bf03033173

Raza, S. S., Khan, M. M., Ahmad, A., Ashafaq, M., Islam, F., Wagner, A. P., et al. (2013). Neuroprotective effect of naringenin is mediated through suppression of NF- $\mathrm{KB}$ signaling pathway in experimental stroke. Neuroscience 230, 157-171. doi: 10.1016/j.neuroscience.2012.10.041

Rosenfeld, G. (1947). Corante pancrômico para hematologia e citologia clínica: Nova combinacão dos componentes do may Grunwald e do Giemsa num só corante de emprego prático. Mem. Inst. Butantan 20, 329-335.

Schinella, G., Mosca, S., Cienfuegos-Jovellanos, E., Pasamar, A. M., Muguerza, B., Ramón, D., et al. (2010). Antioxidant properties of polyphenol-rich cocoa products industrially processed. Food Res. Int. 43, 1614-1623. doi: 10.1016/j. foodres.2010.04.032

Shahidi, F., and Ambigaipalan, P. (2015). Phenolics and polyphenolics in foods, beverages and spices: antioxidant activity and health effects-a review. J. Funct. Foods 18, 820-897. doi: 10.1016/j.jff.2015.06.018

Shi, X., Cai, X., Di, W., Li, J., Xu, X., Zhang, A., et al. (2017). MFGE8 selectively inhibited $\mathrm{A} \beta$-induced microglial M1 polarization via NF- $\kappa \mathrm{B}$ and PI3K-Akt pathways. Mol. Neurobiol. 54, 7777-7788. doi: 10.1007/s12035-016$0255-y$

Shi, Y., and Holtzman, D. M. (2018). Interplay between innate immunity and Alzheimer disease: APOE and TREM2 in the spotlight. Nat. Rev. Immunol. 18, 759-772. doi: 10.1038/s41577-018-0051-1

Silva, V. D., Pitanga, B. P., Nascimento, R. P., Souza, C. S., Coelho, P. L., Menezes-Filho, N., et al. (2013). Juliprosopine and juliprosine from prosopis juliflora leaves induce mitochondrial damage and cytoplasmic vacuolation on cocultured glial cells and neurons. Chem. Res. Toxicol. 26, 1810-1820. doi: $10.1021 /$ tx4001573

Souza, S. C., Paulsen, B. S., Devalle, S., Costa, S. L., Borges, H. L., and Rehen, S. K. (2015). Commitment of human pluripotent stem cells to a neural lineage is induced by the pro-estrogenic flavonoid apigenin. Adv. Regen. Biol. 2:29244. doi: 10.3402/arb.v2.29244

Stewart, C. R., Stuart, L. M., Wilkinson, K., Van Gils, J. M., Deng, J., Halle, A., et al. (2010). CD36 ligands promote sterile inflammation through assembly of a toll-like receptor 4 and 6 heterodimer. Nat. Immunol. 11, 155-161. doi: $10.1038 /$ ni. 1836

Streit, W. J. (2005). Microglia and neuroprotection: implications for Alzheimer's disease. Brain Res. Rev. 48, 234-239. doi: 10.1016/j.brainresrev.2004. 12.013

Taipa, R., Brochado, P., Robinson, A., Reis, I., Costa, P., Mann, D. M., et al. (2017). Patterns of microglial cell activation in Alzheimer disease and frontotemporal lobar degeneration. Neurodegener Dis. 17, 145-154. doi: 10.1159/000 457127

Tang, Y., and Le, W. (2016). Differential roles of M1 and M2 microglia in neurodegenerative diseases. Mol. Neurobiol. 53, 1181-1194. doi: $10.1007 / \mathrm{s} 12035-014-9070-5$

Terahara, N. (2015). Flavonoids in foods: a review. Nat. Prod. Commun. 10, 521-528. doi: 10.1177/1934578X1501000334
Tong, L., Balazs, R., Soiampornkul, R., Thangnipon, W., and Cotman, C. W. (2008). Interleukin-1 $\beta$ impairs brain derived neurotrophic factor-induced signal transduction. Neurobiol. Aging 29, 1380-1393. doi: 10.1016/j. neurobiolaging.2007.02.027

van Horssen, J., Van Schaik, P., and Witte, M. (2019). Inflammation and mitochondrial dysfunction: a vicious circle in neurodegenerative disorders? Neurosci. Lett. 710:132931. doi: 10.1016/j.neulet.2017.06.050

Verkhratsky, A., Olabarria, M., Noristani, H. N., Yeh, C. Y., and Rodriguez, J. J. (2010). Astrocytes in Alzheimer's disease. Neurotherapeutics 7, 399-412. doi: 10.1016/j.nurt.2010.05.017

Vinet, J., Weering, H. R., Heinrich, A., Kälin, R. E., Wegner, A., Brouwer, N., et al. (2012). Neuroprotective function for ramified microglia in hippocampal excitotoxicity. J. Neuroinflammation 9:27. doi: 10.1186/1742-2094-9-27

Xie, L., Lai, Y., Lei, F., Liu, S., Liu, R., and Wang, T. (2015). Exploring the association between interleukin- $1 \beta$ and its interacting proteins in Alzheimer's disease. Mol. Med. Rep. 11, 3219-3228. doi: 10.3892/mmr.2015.3183

Xu, J., Hu, C., Chen, S., Shen, H., Jiang, Q., Huang, P., et al. (2017). Neuregulin1 protects mouse cerebellum against oxidative stress and neuroinflammation. Brain Res. 1670, 32-43. doi: 10.1016/j.brainres.2017.06.012

Zhang, C., Cheng, Y., Wang, H., Wang, C., Wilson, S. P., Xu, J., et al. (2014). RNA interference-mediated knockdown of long-form phosphodiesterase-4D (PDE4D) enzyme reverses amyloid- $\beta 42$-induced memory deficits in mice. J. Alzheimers Dis. 38, 269-280. doi: 10.3233/jad-122236

Zhang, F., Li, F., and Chen, G. (2014). Neuroprotective effect of apigenin in rats after contusive spinal cord injury. Neurol. Sci. 35, 583-588. doi: 10.1007/s10072-013-1566-7

Zhang, K., Ma, Z., Wang, J., Xie, A., and Xie, J. (2011). Myricetin attenuated $\mathrm{MPP}(+)$-induced cytotoxicity by anti-oxidation and inhibition of MKK4 and JNK activation in MES23.5 cells. Neuropharmacology 61, 329-335. doi: 10.1016/j.neuropharm.2011.04.021

Zhang, X., Wang, G., Gurley, E. C., and Zhou, H. (2014). Flavonoid apigenin inhibits lipopolysaccharide-induced inflammatory response through multiple mechanisms in macrophages. PLoS One 9:e107072. doi: 10.1371/journal.pone. 0107072

Zhao, L., Wang, J. L., Liu, R., Li, X. X., Li, J. F., and Zhang, L. (2013). Neuroprotective, anti-amyloidogenic and neurotrophic effects of apigenin in an Alzheimer's disease mouse model. Molecules 18, 9949-9965. doi: 10.3390/molecules18089949

Zotova, E. B., Bharambe, V., Cheaveau, M., Morgan, W., Holmes, C., Harris, S., et al. (2013). Inflammatory components in human Alzheimer's disease and after active amyloid- $\beta 42$ immunization. Brain 136, 2677-2696. doi: 10.1093/brain/awt210

Conflict of Interest: AB is a share-holder in the company "GliaGenesis Limited".

The remaining authors declare that the research was conducted in the absence of any commercial or financial relationships that could be construed as a potential conflict of interest.

Copyright (c) 2020 Dourado, Souza, de Almeida, Bispo da Silva, dos Santos, Silva, De Assis, da Silva, Souza, Costa, Butt and Costa. This is an open-access article distributed under the terms of the Creative Commons Attribution License (CC BY). The use, distribution or reproduction in other forums is permitted, provided the original author(s) and the copyright owner(s) are credited and that the original publication in this journal is cited, in accordance with accepted academic practice. No use, distribution or reproduction is permitted which does not comply with these terms. 